\title{
A Useful Technical Application of the Identification of Nucleotide Sequence Polymorphisms and Gene Resources for Cinnamomum osmophloeum Kaneh. (Lauraceae)
}

\author{
Wen-Kuang Hsu ${ }^{1}$, Shih-Chieh Lee ${ }^{1} \mathbb{D}$ and Pei-Luen Lu ${ }^{2, *}$ \\ 1 Department of Food Science and Biotechnology, DAYEH University, Changhua 51591, Taiwan; \\ andyhsu@mail.dyu.edu.tw (W.-K.H.); slee@mail.dyu.edu.tw (S.-C.L.) \\ 2 Department of Life Sciences, National Taitung University, Taitung 95092, Taiwan \\ * Correspondence: peiluen@nttu.edu.tw; Tel.: +886-89-517960; Fax: +886-89-517986
}

Received: 31 January 2019; Accepted: 1 April 2019; Published: 3 April 2019

\begin{abstract}
The plant genus Cinnamomum contains economically important evergreen aromatic trees and shrubs belonging to the laurel family, Lauraceae. Our study tree species Cinnamomum osmophloeum Kaneh. (CO) has high economic value in Taiwan. The present study attempts to identify the gene resources of Cinnamomum osmophloeum Kaneh. by analyzing the nucleotide sequences of the partial noncoding internal transcribed spacer 2 (pITS2) of the ribosomal DNA and the trnL-trnF chloroplast genome. Seventy-three geographical strains of Cinnamomum osmophloeum, preserved in the Lien Hua-Chin Research Center of the Forestry Research Institute and the Hua-Lin Forestry Center of Chinese Culture University, were collected and analyzed by PCR amplification and DNA sequencing to study the genetic diversity and nucleotide sequence polymorphisms of the tested specimens. Our results allowed us to accurately identify the lineage of Cinnamomum osmophloeum and to conclude that the strains belonging to the Lien Hua-Chin Research Center had much higher genetic diversity than those preserved in the Hua-Lin Forestry Center. Multiple sequence alignments demonstrated that the variability of the nucleotide sequence polymorphisms for the pITS2 region was higher than those of the trnL intron and trnL-trnF intergenic spacer (IGS) regions among the 73 tested specimens of Cinnamomum osmophloeum. Cluster analyses, using the neighbor-joining and maximum parsimony methods, for the 73 tested geographical strains of Cinnamomum osmophloeum and species of Cinnamomum registered in the GenBank and EMBL databases were performed to demonstrate the genus and species distribution of the samples. Here, we describe the use of pITS2 polymorphisms as a genetic classifier and report the establishment of a DNA sequence database for $\mathrm{CO}$ gene resource identification. The sequence database described in this study can be used to identify CO specimens at the inter- or intraspecies level using pITS2 DNA sequences, which illustrates its value in gene resource identification. Our study results can be used further for correctly identifying the true Cinnamomum osmophloeum Kaneh.
\end{abstract}

Keywords: Cinnamomum osmophloeum Kaneh.; gene resource; SNP; ribosomal DNA; chloroplast DNA

\section{Introduction}

Cinnamomum belongs to the Lauraceae and is composed of approximately 350 species of evergreen trees and shrubs [1]. Cinnamon is the dried bark from species of Cinnamomum, such as C. cassia (L.) J.Presl and C. verum J.Presl. The former is from the southern part of the Chinese mainland, specifically Guangdong, Guangxi, Hainan, and Yunnan; the latter originates largely from Ceylon and India [2]. The essential oils extracted from the barks of these plants include cinnamaldehyde, coumarin, 
cinnamyl alcohol and eugenol; these compounds are used not only as medicinal ingredients but also as ingredients in stomachic agents, carminatives, astringents, food, drinks, cosmetics, spices, and preservatives [3]. For the past thirty years, Taiwan's indigenous Cinnamomum osmophloeum Kaneh. (CO) has been used widely as a substitute for C. cassia because of the similarities in the chemical compositions of the essential oils from these plants. Studies of the essential oils extracted from CO leaves have demonstrated their excellent insecticidal [4-6], antibacterial [7,8], antifungal [9,10], anti-inflammatory [11-16] and potential use as a medicinal material for decreasing high uric acid and high blood sugar $[17,18]$. Cinnamomum osmophloeum leaves can be collected and essential oils extracted without damaging the trees, and the annual harvest is highly profitable.

Cinnamomum osmophloeum is a species endemic to Taiwan. There are many geographic strains specific to different growing areas. Ta-Wei Hu and his colleagues set up a garden in the Hua-Lin Forestry Center of Chinese Culture University in 1985 to maintain superior strains of CO. In 1992, a preserved site was built, and many geographical strains of $\mathrm{CO}$ were collected and maintained systematically at the Lien Hua-Chin Research Center of the Forest Research Institute [19]. The Hua-Lin Forestry Center (HL) and Lien Hua-Chin Research Center (LHC) have collected large numbers of geographic strains of $\mathrm{CO}$, and these collections are an important material resource for studying indigenous $\mathrm{CO}$. While geographical strains of $\mathrm{CO}$ are similar in appearance, the variation in the essential oil content of their leaves is substantial. Based on the main constituents of the leaf essential oils and cluster analyses of their relative contents, $\mathrm{CO}$ has been classified into nine chemotypes, as follows: cassia (80\% cinnamaldehyde and 10\% coumarin), cinnamaldehyde, coumarin, linalool, eugenol, camphor cinnamaldehyde/cinnamyl acetate, cinnamyl acetate, linalool, camphor, 4-terpinenol, linalool-terpinenol, and mixed [20,21].

Traditionally, species identification is based on the morphological or histological characterization of the tree or shrub. However, identification based on morphological characteristics alone is difficult due to the morphological similarities between plants. Recently, DNA sequence comparisons of internal transcribed spacers (ITSs) have become widely used as an improved method of species identification [22,23]. The ITSs of ribosomal DNA includes two segments, ITS1 and ITS2, which are divided by the 5.8 rDNA sequence. The lengths of the ITS1 and ITS2 sequences in angiosperms are between 187-298 bp and 187-252 bp, respectively. The variation in length of these regions facilitates the authentication process because they are usually shorter than $300 \mathrm{bp}$ for most of the species examined to date; thus, they can be directly amplified and sequenced. For example, the sequence variations in ITS2 were sufficient to allow researchers to differentiate among medicinal Dendrobium species [24]. Recently, fifty-five processed medicinal herbs belonging to forty-eight families were successfully authenticated using ITS2 with specific primers [25]. ITS sequences can be used as species identification codes through the publicly available sequence domains, such as GenBank and EMBL. With molecular source identification technology, we can study associations not only between variations in DNA sequences and evolutionary relationships among species, but also perform the molecular authentication of traditional Chinese medicines at the interspecies, or even intraspecies, level [26].

In addition to the ITS regions of ribosomal DNA, universal primers have been proposed for the amplification of the trnL (UAA) intron and the trnL-trnF (GAA) intergenic spacer (IGS) from the noncoding regions of chloroplast DNA [27]. Because noncoding regions have faster rates of evolution [28], these loci have been successfully used as markers for both phylogenetic and gene diversity studies of plant species at the genus and species levels [29,30]. Indeed, this feature of noncoding regions also provides an opportunity for species identification. Cinnamon species have been identified genetically by analyzing the nucleotide sequences of trnL-trnF chloroplast DNA from four species: Cinnamomum cassia (L.) J.Presl and C. verum J.Presl., C. burmannii (Nees \& T.Nees) Blume, and C. sieboldii (Makino) Hatus [31]. Tsai et al. [32] have reported the use of the trnL intron and the trnL-trnF intergenic spacer (IGS) in the chloroplast genome and have established a DNA sequence database for the forensic identification of popular plant species in Taiwan. 
We have previously described the DNA barcoding of CO based on the pITS2 region of ribosomal genes $[33,34]$. Seven representative geographical strains, belonging to six different chemotypes of $\mathrm{CO}$, were used to study genetic diversity. Our results indicated that the pITS2 nucleotide sequences for all seven of the geographical strains are not correlated with essential oil composition. The pITS2 sequences were sufficient for the barcoding of $\mathrm{CO}$, while we found that additional genes needed to be analyzed to identify the samples of various chemotypes. Surprisingly, nucleotide sequence polymorphisms in the pITS2 regions from geographical strains of $\mathrm{CO}$ were observed when we tested additional specimens from the LHC of the Forestry Research Institute in our later experiments. In the present study, the identification of the gene resources, genetic diversity, and nucleotide sequence polymorphisms for 73 geographical strains of CO were determined using the ITS2 locus of ribosomal DNA and the trnL-trnF locus of the chloroplast genome.

\section{Materials and Methods}

\subsection{Source of Samples and Their Treatment}

The fourteen geographical strains (coded as "CO"- followed by a letter) of C. osmophloeum Kaneh. that were used in the present study were collected by Ta-Wei Hu and his colleagues from various locations in Taiwan and were planted in the Lien Hua-Chin Research Center located in central Taiwan in 1992 [19]. Another 59 geographical strains of CO (used in this experiment and coded with numbers) from the Hua-Lin Forestry Center of Chinese Culture University located in the northern part of Taiwan were also collected by Ta-Wei Hu and his colleagues in 1985. All of the leaves were authenticated by Fu-Yuan Lu in the Department of Forestry and Natural Resources at the National Chiayi University. The leaves were dehydrated, divided into air-permeable bags and stored dry in sealed containers. Voucher specimens were deposited in the Department of Forestry and Nature Resources at the National Chiayi University. We obtained partial fragments of the ITS2, trnL-trnF IGS and trnL intron; any distinct PCR product that was visualized by agarose gel electrophoresis on at least three occasions for each of the geographical strains was directly sequenced. All of the nucleotide sequence data reported in this paper appeared in the DDBJ/EMBL/GenBank nucleotide sequence databases under the accession numbers shown in Table 1. (Accession numbers will be provided upon the acceptance of the manuscript.) See Table 1 for the species names, codes and GenBank accession numbers of the specimens used in this study.

Table 1. The list of the tested plant species names with three amplified partial nuclear regions pITS2, chloroplast regions trnL intron and trnL-trnF IGS, and GenBank Accession number indicated with base pair lengths. Letter in bold is amplified by this study.

\begin{tabular}{|c|c|c|c|}
\hline \multirow{2}{*}{ Species (Code and Location) } & \multicolumn{3}{|c|}{ GenBank Accession Number (Length: bp) } \\
\hline & pITS2 & trnL Intron & trnL-trnF IGS \\
\hline \multicolumn{4}{|l|}{ (A) Present Study } \\
\hline \multicolumn{4}{|l|}{ Cinnamomum osmophloeum Kaneh. } \\
\hline 1. $\mathrm{CO}-\mathrm{B} 2^{1}$ & $\mathrm{~A}(170)$ & $\mathrm{A}^{10}(464)$ & $A^{12}(356)$ \\
\hline 2. $\mathrm{CO}-\mathrm{C} 1$ & A (158) & & \\
\hline 3. CO-D6 & A (158) & & \\
\hline 4. CO-G19 & A (158) & & \\
\hline 5. CO-K & A (158) & & \\
\hline 6. CO-L & A (158) & & \\
\hline 7. CO-LL & A (161) & & \\
\hline 8. CO-M09 & $\mathrm{A}(162)$ & & \\
\hline 9. CO-P2 & A (162) & & \\
\hline 10. CO-S4 & A (167) & & \\
\hline 11. CO-SE3 & A (162) & & \\
\hline
\end{tabular}


Table 1. Cont.

\begin{tabular}{|c|c|c|c|}
\hline \multirow{2}{*}{ Species (Code and Location) } & \multicolumn{3}{|c|}{ GenBank Accession Number (Length: bp) } \\
\hline & pITS2 & trnL Intron & trnL-trnF IGS \\
\hline 12. CO-SP1 & A (162) & & \\
\hline 13. CO-T3 & A (162) & & \\
\hline 14. $\mathrm{CO}-\mathrm{Z}$ & A (162) & & \\
\hline 15. CO-002 2 & A (170) & & \\
\hline 16. CO-003 & $\mathrm{A}^{3}(170)$ & & \\
\hline 17. CO-004 & $\mathrm{A}(170)$ & A (464) & \\
\hline 18. CO-007 & A (170) & & \\
\hline 19. CO-008 & A (170) & $\mathrm{A}^{11}(464)$ & \\
\hline 20. CO-009 & A (170) & & \\
\hline 21. CO-010 & $\mathrm{A}^{4}(170)$ & & \\
\hline 22. CO-011 & $\mathrm{A}(170)$ & & \\
\hline 23. CO-014 & A (170) & & \\
\hline 24. CO-016 & $\mathrm{A}^{5}(170)$ & & \\
\hline 25. CO-021 & A (170) & & \\
\hline 26. CO-023 & $\mathrm{A}(170)$ & & \\
\hline 27. CO-024 & $\mathrm{A}^{6}(170)$ & & \\
\hline 28. CO-025 & $\mathrm{A}^{7}(170)$ & & \\
\hline 29. CO-028 & $\mathrm{A}^{8}(170)$ & A (465) & \\
\hline 30. CO-030 & $\mathrm{A}(171)$ & & \\
\hline 31. CO-031 & & & $\mathrm{A}^{13}(357)$ \\
\hline 32. $\mathrm{CO}-033$ & A (170) & & \\
\hline 33. CO-038 & A (170) & & \\
\hline 34. CO-040 & A (170) & & \\
\hline 35. CO-042 & $\mathrm{A}^{9}(170)$ & & \\
\hline 36. CO-051 & & & A (356) \\
\hline 37. CO-052 & & & A (357) \\
\hline 38. CO-062 & & & A (358) \\
\hline 39. CO-067 & & A (464) & $\mathrm{A}^{14}(361)$ \\
\hline 40. CO-069 & & & $\mathrm{A}(361)$ \\
\hline 41. CO-071 & & A (464) & \\
\hline 42. CO-083 & & A (464) & \\
\hline 43. CO-097 & & A (464) & \\
\hline 44. CO-098 & & A (465) & \\
\hline 45. CO-102 & A (170) & & \\
\hline 46. CO-105 & A (171) & & \\
\hline 47. CO-122 & A (170) & & \\
\hline 48. CO-123 & A (170) & & \\
\hline 49. CO-124 & & A (464) & \\
\hline \multicolumn{4}{|l|}{ (B) GenBank } \\
\hline C. burmannii & & AB040087 (464) & AB040077 (349) \\
\hline C. burmannii-CB(TW-Nantou) & GQ255636 (170) & $\mathrm{A}^{15}(464)$ & $\mathrm{A}^{15}(356)$ \\
\hline C. burmannii (CN-YZR) & & DQ822590 (464) & \\
\hline C. camphora & AF272260 (169) & AB040091 (464) & AB040081 (349) \\
\hline C. camphora var. glaucescens & & AB040090 (464) & \\
\hline C. Cassia & & AB040085 (464) & \\
\hline C. Cassia-CC1(CN-Fukan) & GQ255627 (169) & $\mathrm{A}^{15}(464)$ & $\mathrm{A}^{15}(356)$ \\
\hline C. Cassia-CC2(CN-Fukan) & GQ255628 (169) & $\mathrm{A}^{15}(464)$ & $\mathrm{A}^{15}(356)$ \\
\hline C. Cassia-CC3(CN-Guangdong) & GQ255629 (169) & $\mathrm{A}^{15}(465)$ & $\mathrm{A}^{15}(356)$ \\
\hline C. Cassia-CC4(CN-Guangdong) & GQ255630 (169) & $\mathrm{A}^{15}(464)$ & $\mathrm{A}^{15}(356)$ \\
\hline C. Cassia-CC5(CN-Fukan) & GQ255631 (169) & $\mathrm{A}^{15}(464)$ & $\mathrm{A}^{15}(356)$ \\
\hline C. cassia $(\mathrm{v}-015)$ & & & AB054228 (356) \\
\hline C. cinnamomifolium & AF272262 (170) & & \\
\hline C. daphnoides & & AB040092 (464) & AB040082 (349) \\
\hline C. doederleinii & & AB040089 (464) & AB040079 (349) \\
\hline
\end{tabular}


Table 1. Cont.

\begin{tabular}{|c|c|c|c|}
\hline \multirow{2}{*}{ Species (Code and Location) } & \multicolumn{3}{|c|}{ GenBank Accession Number (Length: bp) } \\
\hline & pITS2 & trnL Intron & trnL-trnF IGS \\
\hline C. porrectum (C. inunctum) (MID) & & DQ822587 (464) & \\
\hline $\begin{array}{l}\text { C. insulari-montanum }(\text { C. } \\
\text { japonicum })\end{array}$ & AF272263 (168) & AB040093 (464) & AB040083 (349) \\
\hline C. insulari-montanum (CN-YZR) & & DQ822589 (464) & \\
\hline C. loureiroi-CL(VN-Thanh Hoa) & GQ255632 (169) & $\mathrm{A}^{15}(464)$ & $\mathrm{A}^{15}(356)$ \\
\hline C. micranthum & & & EU333285 (356) \\
\hline C. micranthum(i-123) & & & AM050466 (328) \\
\hline C. micranthum(TW-Fuli) & & & EU338493 (356) \\
\hline C. micranthum(TW-Hsiukuluan) & & & EU338495 (356) \\
\hline C. micranthum(TW-Tahu) & & & EU338491 (355) \\
\hline C. micranthum(TW-Yuli) & & & EU338499 (356) \\
\hline C. micranthum(TW-Yungfeng) & & & EU338497 (356) \\
\hline C. dubium (C. multiflorum) (MID) & & DQ822586 (464) & \\
\hline C. bejolghota (C. obtusifolium) (MID) & & DQ822588 (464) & \\
\hline C. sieboldii (C. okinawense) & & AB040094 (464) & AB040084 (349) \\
\hline C. oleifolium & AF272264 (170) & & \\
\hline C. osmophloeum-D4(TW-Nantou) & GQ255635(170) & & \\
\hline C. philippinense & & & AM050463 (328) \\
\hline C. pittosporoides & DQ124269 (168) & & \\
\hline C. quadrangulum & AF272265 (146) & & \\
\hline C. tamala (MID) & & DQ822585 (464) & \\
\hline C. sieboldii & & AB040088 (464) & AB040078 (349) \\
\hline C. verum & AF272267 (171) & & AF268709 (334) \\
\hline C. wilsonii(CN-YZR) & & DQ822592 (464) & \\
\hline C. verum (C. zeylanicum) & & AB040086 (464) & \\
\hline C. verum -CZ(SL-Colombo) & GQ255634 (167) & $\mathrm{A}^{15}(464)$ & $\mathrm{A}^{15}(356)$ \\
\hline C. verum $(\mathrm{v}-005)$ & & AB054243 (464) & AB054235 (356) \\
\hline C. verum (v-006) & & AB054242 (464) & \\
\hline
\end{tabular}

\begin{abstract}
${ }^{1}$ Sample numbers 1-14 with letter codes were collected from LHC. ${ }^{2}$ Sample numbers $15-49$ with number codes were collected from HL. ${ }^{3}$ The pITS2 nucleotide sequence of CO-003 is homologous to that of CO-005. ${ }^{4}$ The pITS2 nucleotide sequence of CO-010 is homologous to that of $\mathrm{CO}-026,037 .{ }^{5}$ The pITS2 nucleotide sequence of CO-016 is homologous to that of CO-128. ${ }^{6}$ The pITS2 nucleotide sequence of CO-024 is homologous to that of CO-031 and 034. ${ }^{7}$ The pITS2 nucleotide sequence of CO-025 is homologous to that of CO-032. ${ }^{8}$ The pITS2 nucleotide sequence of CO-028 is homologous to that of CO-029, 051, 053, 055, 069, 070, 071, 073, 075, 078, 084, 092, 098, 107, 117, 124, 125, 127,129 and $130 .{ }^{9}$ pITS2 nucleotide sequence of CO-042 is homologous to that of CO-042, 045, 047, 048, 050, 052, $053,058,060,061,062,067,090,096,097,099,120$ and $126 .{ }^{10}$ A typical trnL intron sequence; this group of sequences includes CO-B2, C1, D6, E2, G19, K, L, LL, M9, P2, S4, SE3, SP and Z, as well as CO-002, 003,005, 007, 009, 010, 014, 016, 021, 023, 024, 025, 029, 030, 031, 032, 033, 034, 037, 038, 042, 045, 051, 055, 069, 070, 073, 075, 078, 083, 092, 105 , $107,117,120,122,123,128,129$ and $130 .{ }^{11}$ The trnL intron sequence of CO-008 is homologous to that of CO-T3, as well as CO-011, 026, 040, 047, 048, 050, 052, 053, 058, 060, 061, 062, 084, 090, 096, 099 and 102. ${ }^{12}$ A typical trnL-trnF IGS sequence; this group of sequences includes CO-B2, C1, D6, E2, G19, K, L, LL, M9, P2, S4, SE3, SP1, T3 and Z, as well as CO-002, 003, 004, 005, 007, 008, 009, 010, 011, 014, 016, 021, 023, 024, 025, 026, 028, 029, 030, 032, 033, 034, $037,038,040,042,045,047,048,053,055,058,060,061,073,075,078,083,084,090,092,096,097,098,099,102,105$, $107,117,120,122,123,124,126,127,128,129$ and $130 .{ }^{13}$ The trnL-trnF IGS sequence of CO-031 is homologous to that of CO-050, 070 and $125 .{ }^{14}$ The trnL-trnF IGS sequence of CO-067 is homologous to that of CO-071. ${ }^{15}$ The present study.
\end{abstract}

\title{
2.2. DNA Extraction, Polymerase Chain Reaction (PCR), and DNA Sequencing
}

Genomic DNA was isolated according to a modified cetyl trimethyl ammonium bromide (CTAB) approach with minor modifications [35]. Briefly, $100 \mathrm{mg}$ of the dried leaf material was ground into a fine powder in liquid nitrogen using a mortar and pestle. After the addition of $1 \mathrm{~mL}$ of prewarmed extraction buffer (100 mM Tris-HCl, [pH 8.0], $20 \mathrm{mM}$ EDTA, $1 \mathrm{M} \mathrm{NaCl}, 1 \% \mathrm{CTAB}, 1 \% \mathrm{PVP}-40)$, the mixture was incubated in a water bath at $65^{\circ} \mathrm{C}$ or 20 minutes (min) with gentle shaking. The sample solution was mixed with an equal volume of chloroform: isoamyl alcohol (24: 1) and centrifuged at $11,000 \times g$ for $20 \mathrm{~min}$ at $4{ }^{\circ} \mathrm{C}$. The supernatant was transferred to a new Eppendorf tube containing $2 \mathrm{~mL}$ of precipitation buffer (50 mM Tris- $\mathrm{HCl}$ [pH 8.0], $10 \mathrm{mM} \mathrm{EDTA}, 40 \mathrm{mM} \mathrm{NaCl}, 1 \% \mathrm{CTAB}$ ), incubated at 
room temperature for 1 hour $(\mathrm{h})$, and centrifuged at $11,000 \times g$ for $15 \mathrm{~min}$ at $4{ }^{\circ} \mathrm{C}$. The supernatant was carefully decanted, and the pellet was gently suspended in $350 \mathrm{~mL}$ of $1.2 \mathrm{M} \mathrm{NaCl}$ with $10 \mathrm{mg} / \mathrm{mL}$ RNase A. After incubation at $37^{\circ} \mathrm{C}$ for $30 \mathrm{~min}$, an extraction with $350 \mathrm{~mL}$ of chloroform: isoamyl alcohol (24:1) was performed, and the aqueous phase was transferred to a new tube. Then, $3 \mathrm{mM}$ sodium acetate (one-tenth of the recovered volume) and 95\% ethanol (equal to twice the recovered volume) were added to precipitate the DNA. After centrifugation at $12,000 \times g$ for 20 minutes, the DNA pellet was washed with $1 \mathrm{~mL}$ of $70 \%$ ethanol, dried and dissolved in a volume of 50 to $100 \mathrm{~mL}$ of TE buffer.

The pITS2 fragments of the 73 geographical strains of $\mathrm{CO}$ were amplified using the BEL-1/BEL-3 primer set designed by Chiou et al. [25]. The trnL-trnF IGS and trnL intron were amplified by PCR. The " $\mathrm{e}$ " and " $\mathrm{f}$ " primers and the " $\mathrm{c}$ " and " $\mathrm{d}$ " primers were used for the trnL-trnF IGS and the trnL intron, respectively [27]. A schematic diagram of the rDNA ITS, trnL-trnG IGS and trnL intron regions are shown in Figure 1, and the designed primers and their nucleotide sequences are shown in Table 2. PCR amplification of the pITS2, trnL-trnG IGS and trnL intron fragments was carried out as described below. A total volume of $25 \mathrm{~mL}$ of prepared solution, containing $2 \mathrm{~mL}$ of template DNA (40-80 ng), $2.5 \mathrm{~mL}$ of $10 \times$ PCR reaction buffer, $1 \mathrm{~mL}$ of $25 \mathrm{mM} \mathrm{MgCl}_{2}, 2 \mathrm{~mL}$ of $2.5 \mathrm{mM}$ dNTPs, $0.5 \mathrm{~mL}$ of $10 \mathrm{mM}$ forward primer, $0.5 \mathrm{~mL}$ of $10 \mathrm{mM}$ reverse primer, $0.15 \mathrm{~mL}$ ( 5 units) of Taq DNA polymerase (Geneaid Biotech Ltd.; Taipei, Taiwan), $2 \mathrm{~mL}$ of betaine and $13.35 \mathrm{~mL}$ of sterile distilled water, was used for each PCR solution. For the amplification of ITS2, the template DNA was denatured at $95^{\circ} \mathrm{C}$ for $5 \mathrm{~min}$ and then subjected to 40 cycles of $95{ }^{\circ} \mathrm{C}$ for 30 seconds (s), $55^{\circ} \mathrm{C}$ for $30 \mathrm{~s}$, and $72{ }^{\circ} \mathrm{C}$ for $45 \mathrm{~s}$. The final cycle included an extension at $72{ }^{\circ} \mathrm{C}$ for $10 \mathrm{~min}$. For the amplification of the trnL-trnG IGS and $\operatorname{trnL}$ intron, the template DNA was denatured at $95^{\circ} \mathrm{C}$ for $5 \mathrm{~min}$ and then subjected to 35 cycles of $95{ }^{\circ} \mathrm{C}$ for $30 \mathrm{~s}, 50^{\circ} \mathrm{C}$ for $30 \mathrm{~s}$, and $72{ }^{\circ} \mathrm{C}$ for $45 \mathrm{~s}$. The final cycle included an extension at $72{ }^{\circ} \mathrm{C}$ for $10 \mathrm{~min}$. The PCR products were examined by $1.5 \%$ agarose gel electrophoresis and visualized on an ABI3730XL capillary-based DNA sequencer (Applied Biosystems). Samples were purified for sequencing using an ABI PRISM ${ }^{\circledR} 377$ DNA sequencer (Applied Biosystems Industries; Foster City, CA, USA). The obtained sequences were compiled with BioEdit software (version 7.0) [36] and verified by comparison to the in-house and GenBank databases. The obtained sequences published in this paper were deposited in the GenBank databases (GenBank accession numbers will be provided upon the acceptance of the manuscript, see Table 1). Universal primers were used for the amplification of the noncoding regions of chloroplast DNA; the " $\mathrm{e}$ " and " $\mathrm{f}$ " primers were used to amplify the trnL-trnF IGS, whereas the " $\mathrm{c}$ " and " $\mathrm{d}$ " primers were used for the trnL intron (see Table 2 for the primer sequences) [27].

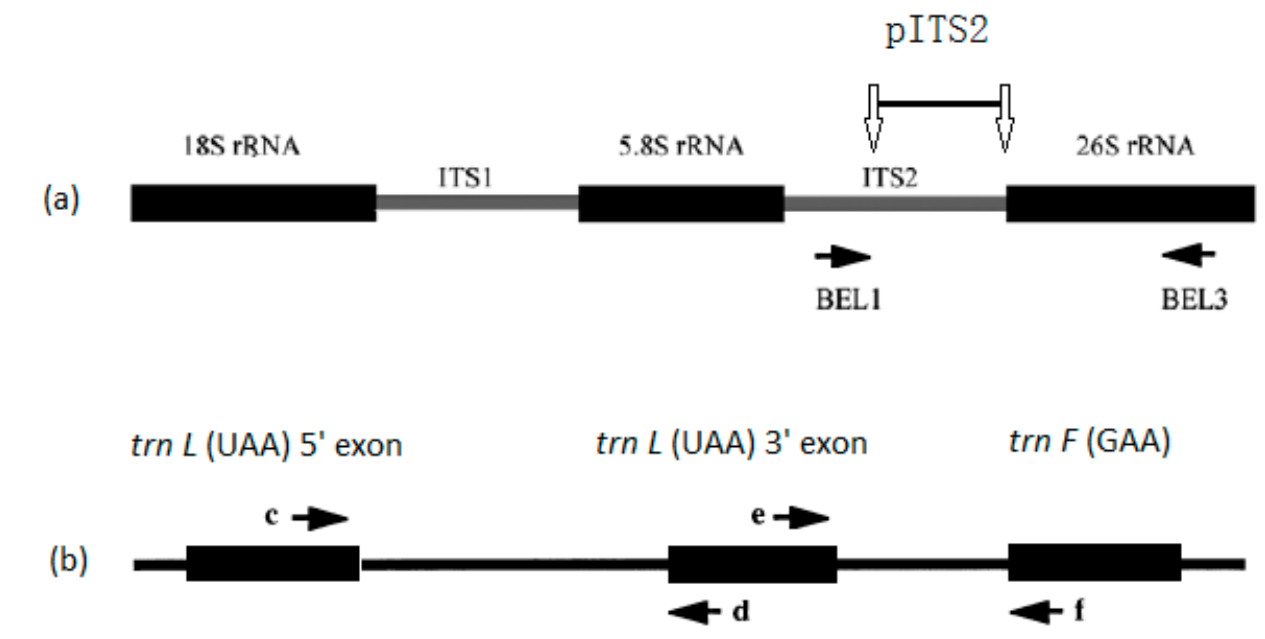

Figure 1. The positions and directions of the PCR amplification and sequencing primers used in the present study. (a) A diagram of the rDNA pITS2 regions and the designed primers; (b) a diagram of the trnL-trnF chloroplast DNA regions and the designed primers. The head and tail of each arrow indicate the $3^{\prime}$ and $5^{\prime}$ end of each primer, respectively. The boxed areas represent coding regions. 
Table 2. The sequences of the primers used in this study to amplify the three noncoding regions.

\begin{tabular}{ccc}
\hline Primers $^{\mathbf{1}}$ & Sequence $\left(\mathbf{5}^{\prime}-\mathbf{3}^{\prime}\right)$ & Design \\
\hline BEL-1 & GGDGCGGAKAHTGGCCYCCCGTGC & {$[25]$} \\
BEL-3 & GACGCTTCTCCAGACTACAAT & {$[25]$} \\
c & CGAAATCGGTAGACGCTACG & {$[27]$} \\
d & GGGGATAGAGGGACTTGAAC & {$[27]$} \\
e & GGTTCAAGTCCCTCTATCCC & {$[27]$} \\
f & ATTTGAACTGGTGACACGAG & {$[27]$} \\
\hline
\end{tabular}

${ }^{1}$ The sequences in this table are for the primers shown in Figure $1 .{ }^{2}$ Where D represents A, G or T, K represents G or $\mathrm{T}, \mathrm{H}$ represents $\mathrm{A}, \mathrm{C}$ or $\mathrm{T}$ and $\mathrm{Y}$ represents $\mathrm{T}$ or $\mathrm{C}$.

\subsection{Local DNA Database Establishment and Sequence Analysis}

The sequences of all of the collected samples of the partial ITS2, the chloroplast trnL intron and the trnL-trnF IGS were imported into BioEdit [36] for comparison purposes. MEGA 7.0 [37] was used to construct the phylogenetic trees of the CO and Cinnamomum spp. without an outgroup species, based on the neighbor-joining (NJ) and maximum-parsimony (MP) methods. The default phylogeny test options used to construct the NJ and MP phylogenetic trees were the following: Bootstrap (1000 replicates), seed $=22607$; Gaps/Missing Data-Complete Deletion; Substitution Model-Nucleotide (kimura 2-parameter); Substitution to include-d, Transitions + Transversions; Pattern among Lineages-Same (Homogeneous); and Rate among sites—uniform rates.

\section{Results}

\subsection{Sequence Analysis}

The C. osmophloeum specimens were chosen to cover a wide range of geographical regions in Taiwan. For this study, 14 geographical strains of $\mathrm{CO}$ were collected from the Lien Hua-Chin Research Center of the Forestry Research Institute (LHC), and 59 strains were collected from the Hua-Lin Forestry Center of Chinese Culture University (HL) (Table 1). Figure 1 illustrates these three regions of interest. The primer set (BEL-1 and BEL-3) used was originally designed to amplify the ITS2 region of medicinal plants and worked well for the Cinnamomum spp. in our previous research [25].

The pITS, trnL intron, and trnL-trnF IGS sequences identified in this study, including those sequences determined by the present study or available from GenBank, were aligned using BioEdit software. For the 73 geographical strains of CO studied, we obtained 49, 10, and 7 nonidentical DNA nucleotide sequences for the pITS2, trnL intron, and trnL-trnF IGS regions, respectively, and we obtained 16, 19, and 18 representative nucleotide sequences, respectively, for Cinnamomum spp. from GenBank (Table 1). The length of the PCR products for the pITS2 and trnL-trnF IGS regions were highly diverse among the Cinnamomum spp.; this diversity was greater than that for the trnL intron. The sizes ranged from $146 \mathrm{bp}$ to $171 \mathrm{bp}$ for the pITS2 and from $328 \mathrm{bp}$ to $356 \mathrm{bp}$ for the trnL-trnF IGS, whereas the amplicons were either $464 \mathrm{bp}$ or $465 \mathrm{bp}$ in length for the trnL intron among all of the Cinnamomum spp. For CO, the average lengths for the PCR products of the pITS2, trnL intron, and trnL-trnF IGS sequences were $168.3 \mathrm{bp}, 464.1 \mathrm{bp}$, and $357.8 \mathrm{bp}$, respectively. The variation in the sizes of the PCR products was greatest for the PITS2 region of the CO specimens collected from the LHC, but these same geographical strains appeared to share conserved sequences for the other two regions tested: PCR products of $464 \mathrm{bp}$ and $356 \mathrm{bp}$ for the for $\operatorname{trnL}$ intron and trnL-trnF IGS, respectively. The variation of sequence identity matrix was the greatest for pITS2 among 14 geographical strains of CO collected from LHC. The same specimens of these 14 geographical stains collected from LHC, they are identical for nucleotide sequences in the $\operatorname{trnL-trnF~IGS~and~trnL~intron~regions.~Sequence~analysis~data~}$ of PCR products of the pITS2, trnL intron and trnL-trnF IGS in the present study are shown in Table 3. 
Table 3. The Size Distributions of PCR Products based on one partial nuclear region pITS2, and two chloroplast regions trnL intron and trnL-trnF IGS from the two study sites used in the present study.

\begin{tabular}{|c|c|c|c|}
\hline & pITS2 & trnL Intron & trnL-trnF IGS \\
\hline $\begin{array}{c}\text { (A) Present study } \\
\text { C. osmophloeum Kaneh. } \\
{ }^{1} \text { LHC }\end{array}$ & $\begin{array}{c}{ }^{3} 158-170 \\
\left({ }^{4} \text { Ave }=161.4\right) \\
\left({ }^{5} \mathrm{ID}=0.310-0.872\right) \\
\left({ }^{6} \mathrm{~N}=14\right)\end{array}$ & $\begin{array}{c}464 \\
(\text { Ave }=464) \\
(\mathrm{ID}=1) \\
(\mathrm{N}=1)\end{array}$ & $\begin{array}{c}356 \\
(\text { Ave }=356) \\
(\mathrm{ID}=1) \\
(\mathrm{N}=1)\end{array}$ \\
\hline${ }^{2} \mathrm{HL}$ & $\begin{array}{c}170-171 \\
(\text { Ave }=170.1) \\
(\mathrm{ID}=0.872-0.994) \\
(\mathrm{N}=24)\end{array}$ & $\begin{array}{c}464-465 \\
(\text { Ave }=464.2) \\
(\mathrm{ID}=0.995-0.997) \\
(\mathrm{N}=9)\end{array}$ & $\begin{array}{c}356-361 \\
(\text { Ave }=358.3) \\
(\mathrm{ID}=0.969-0.997) \\
(\mathrm{N}=6)\end{array}$ \\
\hline $\mathrm{LHC}+\mathrm{HL}$ & $\begin{array}{c}158-171 \\
(\text { Ave }=168.3) \\
(\mathrm{ID}=0.310-0.994) \\
(\mathrm{N}=38)\end{array}$ & $\begin{array}{c}464-465 \\
(\text { Ave }=464.1) \\
(\mathrm{ID}=0.995-0.997) \\
(\mathrm{N}=10)\end{array}$ & $\begin{array}{c}356-361 \\
(\text { Ave }=357.8) \\
(\mathrm{ID}=0.969-0.997) \\
(\mathrm{N}=7)\end{array}$ \\
\hline $\begin{array}{l}\text { (B) Cinnamomum spp. } \\
\text { (GenBank) }\end{array}$ & $\begin{array}{c}146-171 \\
(\text { Ave }=167.7) \\
(\mathrm{ID}=0.721-1) \\
(\mathrm{N}=16)\end{array}$ & $\begin{array}{c}464-465 \\
(\text { Ave }=464.0) \\
(\mathrm{ID}=0.993-1) \\
(\mathrm{N}=27)\end{array}$ & $\begin{array}{c}328-356 \\
(\text { Ave }=351.1) \\
(\mathrm{ID}=0.418-1) \\
(\mathrm{N}=26)\end{array}$ \\
\hline
\end{tabular}

\subsection{Nucleotide Sequence Polymorphism of C. osmophloem Kaneh.}

The sequences of all the collected samples of pITS2, trnL intron, and trnL-trnF IGS regions in present study in the present study were imported by the BioEdit software for comparison purposes and intraspecific variations were detected (Figures 2-4). The length of the trnL intron was determined to be $465 \mathrm{bp}$ for geographical strain CO-028. That is different from the normal $464 \mathrm{bp}$ in length. Only three out of 465 positions were not conserved among ten representative strains analyzed. The sequence of CO-097 differed from that of the other strains by one nucleotide substitution at position 391. In the CO-097 sequence, there was a " $\mathrm{T}$ " nucleotide at position 391, while the other strains contained a " $\mathrm{C}$ " at this position (Figure 2). The length of trnL-trnF IGS is from $356 \mathrm{bp}$ to $361 \mathrm{bp}$ among seven representative strains compared. After comparison, 350 out of the 362 positions were conserved. Twelve polymorphic characteristics were observed in the regions between positions 349 to 362 (Figure 3). The length of pITS2 region is relatively short, when compared to those of trnL intron and trnL-trnF IGS for strains in the present study. However, a large intraspecific variation was observed. After sequence alignment and comparison, only 30 out of 180 positions were conserved among 38 representative sequences. Ten insertions of nucleotides were observed at positions in the 4th, 22th, 55th, 56th, 78th, and 79th bp. The deletion of nucleotides was observed at positions in the 6-11th, 32th, 78th, 79th, 117-122th, 146th, and 147 th $\mathrm{bp}$. In total, there were 123 substituted positions, which represented $68.3 \%$ of the total sequence length (Figure 4). 
CO-B2 $(t)$

$\mathrm{CO}-004$

$\mathrm{Co}-008(\mathrm{t})$

$\mathrm{CO}-028$

CO- 067

$\mathrm{CO}-071$

$\mathrm{CO}-083$

$\mathrm{CO}-097$

CO-098

CO-124

Clustal Consensus

CO-B2 (t)

$\mathrm{CO}-004$

$\mathrm{CO}-008(\mathrm{t})$

$\mathrm{CO}-028$

CO-067

CO-071

$\mathrm{CO}-083$

$\mathrm{CO}-097$

CO-098

CO-124

Clustal Consensus

CO-B2 ( $t)$

$\mathrm{CO}-004$

$\mathrm{CO}-008(\mathrm{t})$

$\mathrm{CO}-028$

CO- 067

CO- 071

Co- 083

$\mathrm{CO}-097$

$\mathrm{CO}-098$

CO-124

Clustal Consensus

CO-B2 ( $t$ )

$\mathrm{CO}-004$

$\mathrm{CO}-008(\mathrm{t})$

$\mathrm{CO}-028$

$\mathrm{CO}-067$

CO- 071

$\mathrm{CO}-083$

$\mathrm{CO}-097$

$\mathrm{CO}-098$

$\mathrm{CO}-124$

clustal Consensus

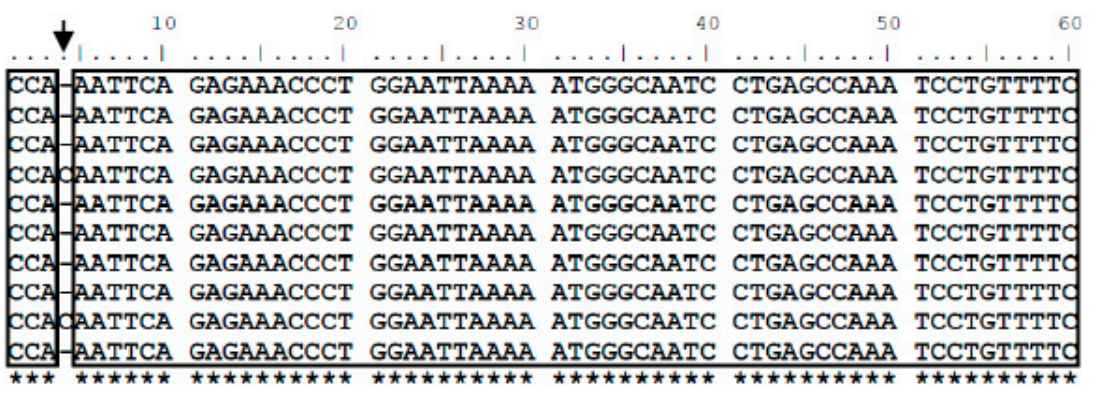

AGAAAACAAG GGTTCAGAAA GCGAGAACCA AAAAAAGGAT AGGTGCAGAG ACTCAAAGGZ AGAAAACAAG GGTTCAGAAA GCGAGAACCA AAAAAAGGAT AGGTGCAGAG ACTCAAAGGZ AGAAAACAAG GGTTCAGAAA GCGAGAACCA CAAAAAGGAT AGGTGCAGAG ACTCAAAgGA AGAAAACAAG GGTTCAGAAA GCGAGAACCA AAAAAAGGAT AGGTGCAGAG ACTCAAAGGA AGAAAACAAG GGTTCAGAAA GCGAGAACCA AAAAAAGGAT AGGTGCAGAG ACTCAAAGGZ AGAAAACAAG GGTTCAGAAA GCGAGAACCA AAAAAAGGAT AGGTGCAGAG ACTCAAAGGA AGAAAACAAG GGTTCAGAAA GCGAGAACCA OAAAAAGGAT AGGTGCAGAG ACTCAAAGGA AGAAAACAAG GGTTCAGAAA GCGAGAACCA DAAAAAGGAT AGGTGCAGAG ACTCAAAGGZ AGAAAACAAG GGTTCAGAAA GCGAGAACCA CAAAAAGGAT AGGTGCAGAG ACTCAAAGGP AGAAAACAAG GGTTCAGAAA GCGAGAACCA AAAAAAGGAT AGGTGCAGAG ACTCAAAGGA

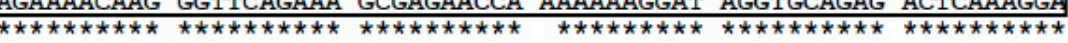

$$
130
$$$$
140
$$

160

170

180

AGCTGTTCTA ACGAATGGAG TTGATTAACA TTGGTATAGG AATCCTTCTA TCGAAATTCO

AGCTGTTCTA ACGAATGGAG TTGATTAACA TTGGTATAGG AATCCTTCTA TCGAAATTCC AGCTGTTCTA ACGAATGGAG TTGATTAACA TTGGTATAGG AATCCTTCTA TCGAAATTCC AgCTGTTCTA ACGAATGgag TTGATtAACA TTGGTATAgg AATCCTTCTA TCGAAATTCC AGCTGTTCTA ACGAATGGAG TTGATTAACA TTGGTATAGG AATCCTTCTA TCGAAATTCC AGCTGTTCTA ACGAATGGAG TTGATTAACA TTGGTATAGG AATCCTTCTA TCGAAATTCC AGCTGTTCTA ACGAATGGAG TTGATTAACA TTGGTATAG AATCCTTCTA TCGAAATTCO AGCTGTTCTA ACGAATGGAG TTGATTAACA TTGGTATAGG AATCCTTCTA TCGAAATTCC AGCTGTTCTA ACGAATGGA TTGATTAACA TTGGTATAGg AATCCTTCTA TCGAAATTCC AGCTGTTCTA ACGAATGGAG TTGATTAACA TTGGTATAGG AATCCTTCTA TCGAAATTCD

$$
200 \quad 210 \quad 220 \quad 230 \quad 240
$$

AGAAAGGATG ACCCTATCCT ATATACGTAC TGAAATATCA AACAATTAAT CACGATCCGZ AGAAAGGATG ACCCTATCCT ATATACGTAC TGAAATATCA AACAATTAAT CACGATCCGA AGAAAGGATG ACCCTATCCT ATATACGTAC TGAAATATCA AACAATTAAT CACGATCCGZ AGAAAGGATG ACCCTATCCT ATATACGTAC TGAAATATCA AACAATTAAT CACGATCCGZ AGAAAGGATG ACCCTATCCT ATATACGTAC TGAAATATCA AACAATTAAT CACGATCCGZ AGAAAGGATG ACCCTATCCT ATATACGTAC TGAAATATCA AACAATTAAT CACGATCCGA AGAAAGGATG ACCCTATCCT ATATACGTAC TGAAATATCA AACAATTAAT CACGATCCGZ AGAAAGGATG ACCCTATCCT ATATACGTAC TGAAATATCA AACAATTAAT CACGATCCGZ AGAAAGGATG ACCCTATCCT ATATACGTAC TGAAATATCA AACAATTAAT CACGATCCGR AGAAAGGATG ACCCTATCCT ATATACGTAC TGAAATATCA AACAATTAAT CACGATCCGZ

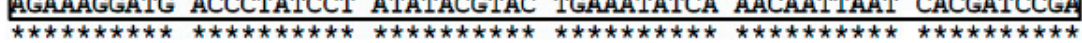

Figure 2. Cont. 


CO-B2 $(t)$
CO-004
CO-008(t)
CO-028
CO-067
CO-071
CO-083
CO-097
CO-098
CO-124
Clustal Consensus

\begin{tabular}{|c|c|c|c|c|c|}
\hline 250 & 260 & 270 & 280 & 290 & 300 \\
\hline & & & & & \\
\hline TTCCGTATTT & TTTTTATATG & AAAAATGGAA & GAATTCTTGT & GAATCGATTC & CAAATTGAAG \\
\hline TTCCGTATTT & TTTTTATATG & AAAAATGGAA & GAATTCTTGT & GAATCGATTC & CAAATTGAAS \\
\hline ITCCGTATTT & TTTTTATATG & AAAAATGGAA & GAATTCTTGT & GAATCGATTC & CAAATTGAAC \\
\hline TTCCGTATTT & TTTTTATATG & AAAAATGGAA & GAATTCTTGT & GAATCGATTC & CAAATTGAAC \\
\hline TTCCGTATTT & TTTTTATATG & AAAAATGGAA & GAATTCTTGT & GAATCGATTC & CAAATTGAAE \\
\hline ITCCGTATTT & TTTTTATATG & AAAAATGGAA & GAATTCTTGT & GAATCGATTC & CAAATTGAAG \\
\hline TTCCGTATTT & TTTTTATATG & AAAAATGGAA & GAATTCTTGT & GAATCGATTC & CAAATTGAAG \\
\hline ITCCGTATTT & TTTTTATATG & AAAAATGGAA & GAATTCTTGT & GAATCGATTC & CAAATTGAAC \\
\hline TTCCGTATTT & TTTTTATATG & AAAAATGGAA & GAATTCTTGT & GAATCGATTC & CAAATTGAAA \\
\hline ITCCGTATTT & & & & GAATCGATTC & 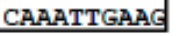 \\
\hline & & & & & \\
\hline
\end{tabular}
ITCCGTATTT TTTTTATATG AAAAATGGAA GAATTCTTGT GAATCGATTC CAAATTGAAG 299 ITCCGTATTT TTTTTATATG AAAAATGGAA GAATTCTTGT GAATCGATTC CAAATTGAAG 300 TITTTTTT TTTATG AAAAATGGAA GAATTCTTGT GAATCGATTC CAAATTGAAG 299 作 ITCCGTATTT TTTTTATATG AAAAATGGAA GAATTCTTGT GAATCGATTC CAAATTGAAG 299 TCCGTATTT TTTTTATATG AAAAATGGAA GAATTCTTGT GAATCGATTC CAAATTGAAG 300 Clustal Consensus

$\begin{array}{rrrrrr}310 & 320 & 330 & 340 & 350 & 360\end{array}$

$\mathrm{CO}-\mathrm{B} 2(\mathrm{t})$

$\mathrm{CO}-004$

Co- $008(t)$

CO- 028

$\mathrm{CO}-067$

$\mathrm{CO}-071$

$\mathrm{CO}-083$

CO-097

$\mathrm{CO}-098$

$\mathrm{CO}-124$

Clustal Consensus

\begin{tabular}{|c|c|c|c|c|c|}
\hline GAAGAATCGA & ATATTCAGTG & ATCAAATCAT & TCACTCCTCG & GATAGATCTT & TTGAAGAACI \\
\hline GAAGAATCGA & ATATTCAGTG & ATCAAATCAT & TСACTCCTCG & GATAGATCTT & TTGAAGAACI \\
\hline GAAGAATCGA & ATATTCAGTG & АТСAAATCAT & ТСACTCCTCG & GATAGATCTT & TTGAAGAACA \\
\hline GAAGAATCGA & ATATTCAGTG & АTCAAATCAT & TСACTCCTCG & GATAGATCTT & TTGAAGAACI \\
\hline GAAGAATCGA & ATATTCAGTG & ATCAAATCAT & TСACTCCTCG & GATAGATCTT & TTGAAGAACT \\
\hline GAAGAATCGA & ATATTCAGTG & ATCAAATCAT & TCACTCCTCG & GATAGATCTT & TTGAAGAACI \\
\hline $\begin{array}{l}\text { GAAGAATCGA } \\
\text { GAAGATCGA }\end{array}$ & ATATTCAGTG & ATCAAATCAT & TCACTCCTCG & GATAGATCTT & TTGAAGAACA \\
\hline $\begin{array}{l}\text { GAAGAATCGA } \\
\text { GAAGATCGA }\end{array}$ & $\begin{array}{l}\text { ATATTCAGTG } \\
\text { ATATTCAGTG }\end{array}$ & $\begin{array}{l}\text { ATCAAATCAT } \\
\text { ATCAAATCAT }\end{array}$ & $\begin{array}{l}\text { TCACTCCICG } \\
\text { TCACTCCTCG }\end{array}$ & GATAGATCTT & TTGAAGAACI \\
\hline GAAGAATCGA & ATATTCAGTG & ATCAAATCAT & TCACTCCTCG & GATAGATCTT & TTGAAGAACI \\
\hline ** $>>2>$ & $* \star$ & & $x$ & 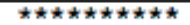 & 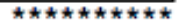 \\
\hline
\end{tabular}

$\mathrm{CO}-\mathrm{B} 2(\mathrm{t})$

$\mathrm{CO}-004$

$\mathrm{CO}-008(\mathrm{t})$

CO-028

$\mathrm{CO}-067$

$\mathrm{CO}-071$

$\mathrm{CO}-083$

$\mathrm{CO}-097$

CO-098

$\mathrm{CO}-124$

Clustal Consensus

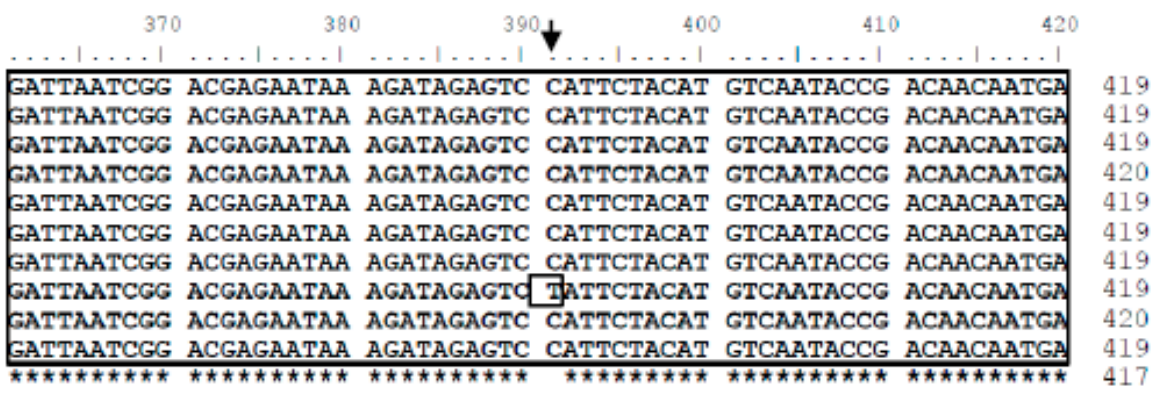

CO-B2 ( $t$ )

$\mathrm{CO}-004$

$\mathrm{CO}-008$ ( $t$ )

$\mathrm{CO}-028$

$\mathrm{CO}-067$

$\mathrm{CO}-071$

$\mathrm{CO}-083$

CO-097

CO-098

CO-124

Clustal Consensus

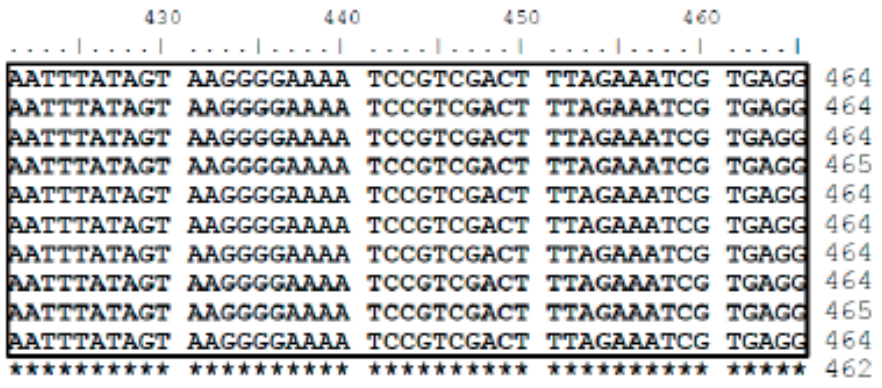

Figure 2. Nucleotide Sequence Polymorphism of C. osmophloem Kaneh. Sequence alignments of the trnL intronic region among the different $C$. osmophloeum Kaneh. varieties used in this study. * is to mean the same base pair. Square is to indicate the special base pair. Arrow is to mean the different base pair. 


CO-B2 $(t)$
CO-031 $(t)$
CO-051
CO-052
CO-062
CO-067(t)
CO-069
Clustal Consensus

$\mathrm{CO}-\mathrm{B} 2(\mathrm{t})$

CO-031 (t)

Co-051

$\mathrm{CO}-052$

CO-062

$\mathrm{CO}-067$ ( $t$ )

Co-069

CO-B2 $(t)$
CO-031(t)
CO-051
CO-052
$C 0-062$
$C 0-067(t)$
CO-069
Clustal Consensus

CO-B2 (t)
CO-031(t)
CO-051
CO-052
CO-062
CO-067(t)
CO-069
Clustal Consensus

CO-B2 (t)

Co-031 $(t)$

CO-051

CO-052

$\mathrm{CO}-062$

$\mathrm{co}-067(\mathrm{t})$

Co-069

Clustal Consensus

$\mathrm{CO}-\mathrm{B} 2(\mathrm{t})$

$\mathrm{CO}-031(\mathrm{t})$

$\mathrm{CO}-051$

$\mathrm{CO}-052$

$\mathrm{CO}-062$

$\mathrm{Co}-067(t)$

Co-069

Clustal Consensus

$\mathrm{CO}-\mathrm{B} 2(\mathrm{t})$

$\mathrm{CO}-031(\mathrm{t})$

$\mathrm{CO}-051$

$\mathrm{CO}-052$

$\mathrm{CO}-062$

Co-067 (t)

CO-069

Clustal Consensus
Clustal Consensus

10
$\ldots \ldots \ldots+\ldots$
CTATCCCCAA TAAAAAGAAA AGAGCCCGTT TTACTACCTA ACCTCTTTAT

$\begin{array}{rrrrr}70 & 80 & 90 & 100 & 110\end{array}$

GTTCCAAATT AGTTATGTTT CTTATTCACT CTACTCTTTC ACAAACGGAT CCGGACAGA GTTCCAAATT AGTTATGTTT CTTATTCACT CTACTCTTTC ACAAACGGAT CCGGACAGAA GTTCCAAATT AGTTATGTTT CTTATTCACT CTACTCTTTC ACAAACGGAT CCGGACAGA GTTCCAAATT AGTTATGTTT CTAATTCACT CTACTCTTTC ACAAACGGAT CCGGACAGA GTTCCAAATT AGTTATGTTT CTTATTCACT CTACTCTTTC ACAAACGGAT CCGGACAGAA GTTCCAAATT AGTTATGTTT CTTATTCACT CTACTCTTTC ACAAACGGAT CCGGACAGAA GTTCCAAATT AGTTATGTTT CTTATTCACT CTACTCTTTC ACAAACGGAT CCGGACAGAN

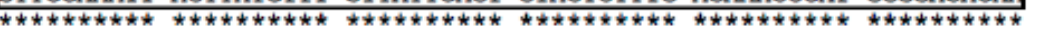$$
130
$$

$$
140
$$$$
160
$$$$
170
$$

180

ACCTTTCTCT CTTATCACAA GTCTATAGAT ACGATATACT TACAAATGAA CATATATAGG ACCTTTCTCT CTTATCACAA GTCTATAGAT ACGATATACT TACAAATGAA CATATATAGG ACCTTTCTCT CTTATCACAA GTCTATAGAT ACGATATACT TACAAATGAA CATATATAGC ACCTTTCTCT CTTATCACAA GTCTATAGAT ACGATATACT TACAAATGAA CATATATAGC ACCTTTCTCT CTTATCACAA GTCTATAGAT ACGATATACT TACAAATGAA CATATATAGG ACCTTTCTCT CTTATCACAA GTCTATAGAT ACGATATACT TACAAATGAA CATATATAGC ACCTTTCTCT CTTATCACAA GTCTATAGAT ACGATATACT TACAAATGAA CATATATAGG

180
180
180
180
180
180
180
180

$\begin{array}{llllll}190 & 200 & 210 & 220 & 230 & 240\end{array}$

CAAGGAATTT CCATTATTAA ATAATTCACA GTCCATATCA TTACTCTTAC ACTGACAAAG CAAGGAATTT CCATTATTAA ATAATTCACA GTCCATATCA TTACTCTTAC ACTGACAAAG CAAGGAATTT CCATTATTAA ATAATTCACA GTCCATATCA TTACTCTTAC ACTGACAAAG CAAGGAATTT CCATTATTAA ATAATTCACA GTCCATATCA TTACTCTTAC ACTGACAAAO CAAGGAATTT CCATTATTAA ATAATTCACA GTCCATATCA TTACTCTTAC ACTGACAAAG CAAGGAATTT CCATTATTAA ATAATTCACA GTCCATATCA TTACTCTTAC ACTGACAAAC CAAGGAATTT CCATTATTAA ATAATTCACA GTCCATATCA TTACTCTTAC ACTGACAAAC

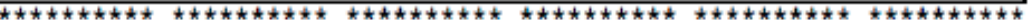

$$
250 \quad 270 \quad 280 \quad 290 \quad 300
$$

TCTTCTTTTT GAAGATCCAA GAAACTCCAA GGCCTAGGTA AGATTTTGTA AGACTTTTTG TCTTCTTTTT GAAGATCCAA GAAACTCCAA GGCCTAGGTA AGATTTTGTA AGACTTTTTE TCTTCTTTTT GAAGATCCAA GAAACTCCAA GGCCTAGGTA AGATTTTGTA AGACTTTTTO TCTTCTTTTT GAAGATCCAA GAAACTCCAA GGCCTAGGTA AGATTTTGTA AGACTTTTTC TCTTCTTTTT GAAGATCCAA GAAACTCCAA GGCCTAGGTA AGATTTTGTA AGACTTTTTG FCTTCTTTTT GAAGATCCAA GAAACTCCAA GGCCTAGGTA AGATTTTGTA AGACTTTTTC TCTTCTTTTT GAAGATCCAA GAAACTCCAA GGCCTAGGTA AGATTTTGTA AGACTTTTT 2.

Figure 3. Nucleotide Sequence Polymorphism of C. osmophloem Kaneh. The Cinnamomum osmophloeum Kaneh. Varieties are shown according to the sequence alignments of the chloroplast trnL-trnF IGS

region used in this study.

$$
320 \quad 330 \quad 340
$$

\section{HWHWH}

GGTTTCTTTA ATTGACATAG ACCCCAGTCC TCTAATAGGG CGATGCATQ CGGAATQGGTTTCTTTA ATTGACATAG ACCCCAGTCC TCTAATAGGG CGATGCATCT CGGAAT- - GGTTTCTTTA ATTGACATAG ACCCCAGTCC TCTAATAGGG CGATGCATCE CGGAATG--GGTTTCTTTA ATTGACATAG ACCCCAGTCC TCTAATAGGG CGATGCATCI GTI IOT CAT

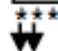

- 356

$-357$

$-\mathbf{3} 56$

$--357$

$-358$

361 GGTTTCTTTA ATTGACATAG ACCCCAGTCC TCTAATAGGG CGATGCAT[I CGGAATC--- 
CO-B2

$\mathrm{CO}-\mathrm{C} 1$

CO-D6

CO-G19

$\mathrm{CO}-\mathrm{K}$

CO-L

CO-LI

CO-M09

CO-P2

$\mathrm{CO}-\mathrm{S} 4$

CO-SE3

CO-SP1

$\mathrm{CO}-\mathrm{T3}$

$\mathrm{CO}-\mathrm{Z}$

CO-002

$\mathrm{CO}-003(t)$

$\mathrm{CO}-004$

$\mathrm{CO}-007$

$\mathrm{CO}-008$

$\mathrm{CO}-009$

CO-010 ( $t$ )

$\mathrm{CO}-011$

CO-014

$\mathrm{Co}-016(\mathrm{t})$

$\mathrm{CO}-021$

$\mathrm{CO}-023$

$\mathrm{CO}-024(t)$

$\mathrm{CO}-025(t)$

Co-028(t)

$\mathrm{CO}-030$

$\mathrm{CO}-033$

$\mathrm{CO}-038$

$\mathrm{CO}-040$

$\mathrm{CO}-042$ ( $t$ )

$\mathrm{CO}-102$

$\mathrm{CO}-105$

CO-122

$\mathrm{CO}-123$

Clustal Consensus

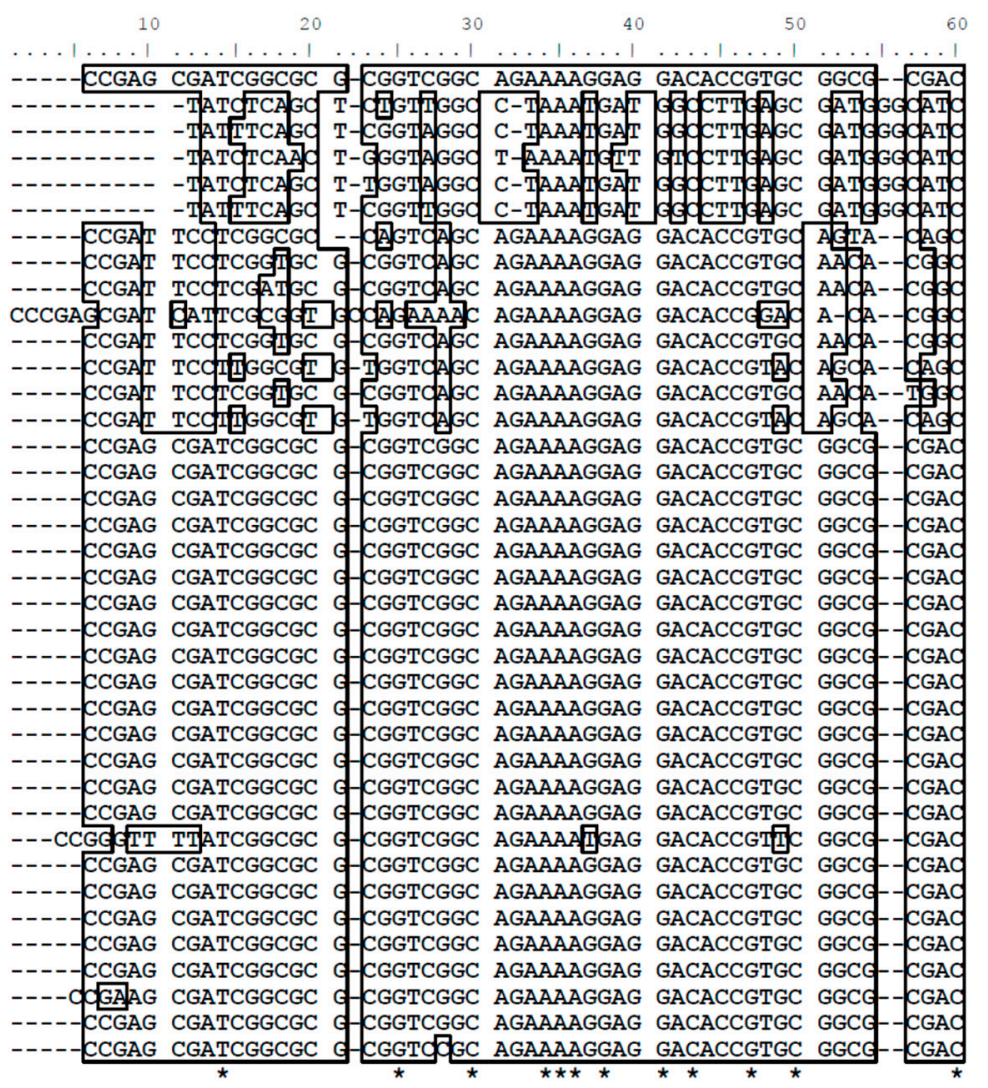

60

$\mathrm{CO}-\mathrm{B} 2$
$\mathrm{CO}-\mathrm{C} 1$

CO-D 6

CO-G19

$\mathrm{CO}-\mathrm{K}$

CO-I

CO-L

CO-LL

CO-P2

$\mathrm{CO}-\mathrm{S} 4$

CO-SE3

CO-SP1

$\mathrm{CO}-\mathrm{T} 3$

CO-Z

$\mathrm{CO}-003$ (t)

CO-004

CO-007

$\mathrm{CO}-008$

CO- 009

$\mathrm{CO}-010$ (t)

CO-011

CO-014

Co-016 (t)

CO-021

$\mathrm{CO}-023$

CO-024 (t)

$\mathrm{CO}-025(t)$

CO-028(t)

CO-030

CO-033

CO-038

$\mathrm{CO}-040$

CO-042 (t)

$\mathrm{CO}-102$

CO-105

CO-122

CO-123

Clustal Consensus

70

80

90

100

110

120

ACGGCGTGTG GGGGITGTGA GAGGCGA IC GTCGCCGATC GTACGTCGCG CCCGCAATCD

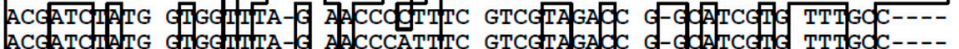

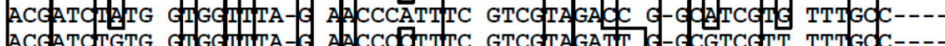

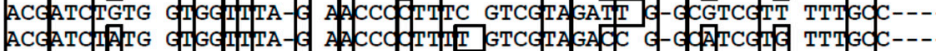

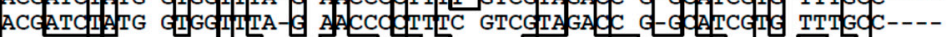

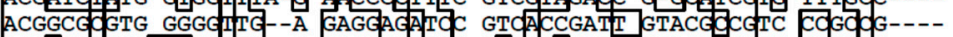

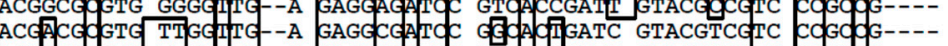

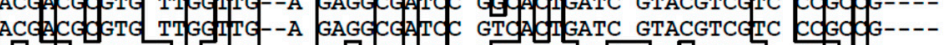

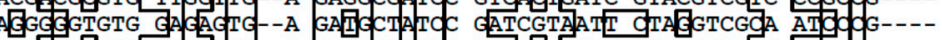

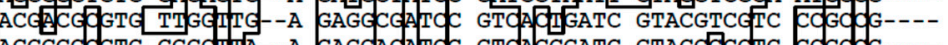

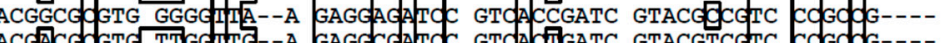

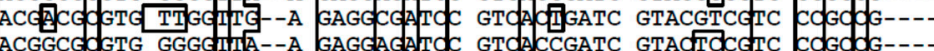
ACGGCG GTG GGGG ACGGCGT G G GGGG IIGGIS AGGGGCA ATC GTCGCCGATC GTACGTCGCG CCCGCAATCC ACGGCGTGTG GGGGIIGTGA GAGGGCA GIC GTCGCCGATC GTACGTCGCG CCCGCAATCO ACGGCGILITG GGGC TÖGTGA GAGGCBA OIC GTCGCCGATC GTACGTCGCG CCCGCAATC

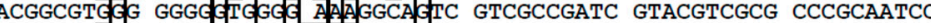
ACGGCGTEG GGG ACGCG ACGCG ACGGCGTGTG GGGG ITGGG GGAGGA ETC GTCGCCGATC GTACGTCGCG CCCGCAATC ACGGCGTGGT GGG GIIGAT A Pa GGCA GIC GTCGCCGATC GTACGTCGCG CCCGCAATCO ACGGCGTGGT GGGGIIGGT G GGGGCA SIC GTCGCCGATC GTACGTCGCG CCCGCAATCC ACGGCGTEGT GGGG IITGIG GaGGGCA GIC GTCGCCGATC GTACGTCGCG CCCGCAATCO ACGGCGTGTT GGGETIGGGA A A GG ACGGCGTGTT GGG STGGA A A GGCA TIC GTCGCCGATC GTACGTCGCG CCCGCAATCO ACGGCGT ACGGCGI GGG I I GIS ACGGCGTGTG GGGG ITGIGA GAGGCGA PIC GTCGCCGATC GTACGTCGCG CCCGCAATC ACGGCGTGTG GGG IIIS-A GAGGCGACOC GTCGCCGATC GTACGTCGCG CCCGCAATCO ACGGCGITIG GGGG IOGIGA GAGGCGA ACGGCGTGGT GGGe 19 GT AGAGGCA GTC GTCGCCGATC GTACGTCGCG CCCGCAATCO ACGGCGTGTG GGGETIGGA A A GGA GTC GTCGCCGATC GTACGTCGCG CCCGCAATCC ACGGCGTGTG GGGCTỎITA GAGGCAATC GTCGCCGATC GTACGTCGCG CCCGCAATC

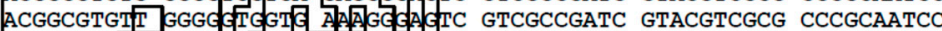
ACGGCGTG GG GGGGIITGTG GAGGGCA GIC GTCGCCGATC GTACGTCGCG CCCGCAATCO ACGGCGEGTG GGG IIGGG AGAGGCA IIC GTCGCCGATC GTACGTCGCG CCCGCAATCO

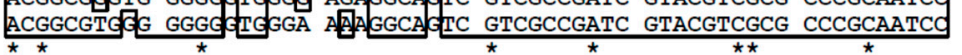

Figure 4. Cont. 


CO-B2
CO-C1
CO-D6
CO-G19
CO-K
CO-L
CO-LL
CO-M09
CO-P2
CO-S4
CO-SE 3
CO-SP1
CO-T3
CO-Z
CO-002
CO-003 (t)
CO-004
CO-007
CO-008
CO-009
CO-010(t)
CO-011
CO-014
CO-016(t)
CO-021
CO-023
CO-024 $(t)$
CO-025 $(t)$
CO-028 $(t)$
CO-030
CO-033
CO-038
CO-040
CO-042 $(t)$
CO-102
CO-105
CO-122
CO-123
Clustal Consensus

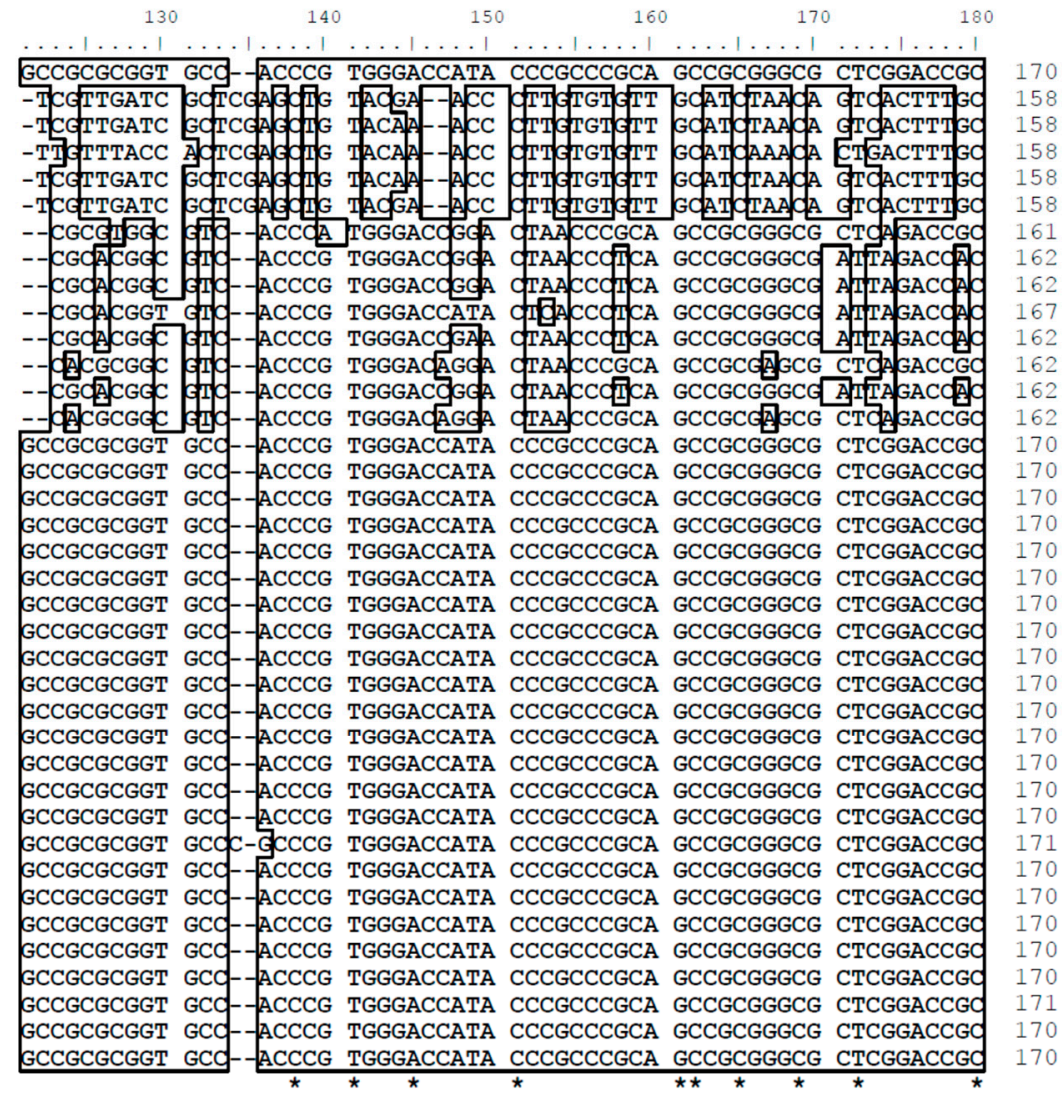

Figure 4. Nucleotide Sequence Polymorphism of C. osmophloem Kaneh. The Cinnamomum osmophloeum Kaneh. Varieties are shown according to the sequence alignments of the nuclear noncoding region pITS2 used in this study.

\subsection{Sequence Analysis of the DNA Database in This Study}

To evaluate the probability that the pITS2, trnL intron, and trnL-trnF IGS regions can be used to identify any sample at the species level, the nucleotide sequences of 18 Cinnamomum spp. collected from 42 different locations were acquired from GenBank (data included was as of January 2019, see Table 1). One representative sequence from each collection site was selected for each species if more than one homologous sequence was deposited in GenBank. These sequences were used to construct our local DNA database. The sequences for the pITS2, $\operatorname{trn} L$ intron, and trnL-trnF IGS regions were aligned separately using the MEGA 7 program, and the results are shown in Figure 5. Our results indicated that the NJ tree constructed from the pITS2 region data had much better resolution than those of the trees constructed from the trnL intron and trnL-trnF IGS sequence data (Figure 5A-C). The sequence variation in the pITS2 region was sufficient not only for the clustering of specimens of the same species, but also for discriminating the geographical strains intraspecifically. The NJ trees constructed from the trnL intron and trnL-trnF IGS sequence data would not be predicted to perform well for species clustering because of the lower sequence variation in these two regions. It should be noted that the strains of CO collected from the LHC and HL were clustered and placed in two separate branches in the NJ tree using the pITS2 sequences. One pITS2 sequence for CO (GQ255635) has already been registered in the GenBank and EMBL databases. Unfortunately, this sequence was not successfully clustered with the other $\mathrm{CO}$ specimens. 


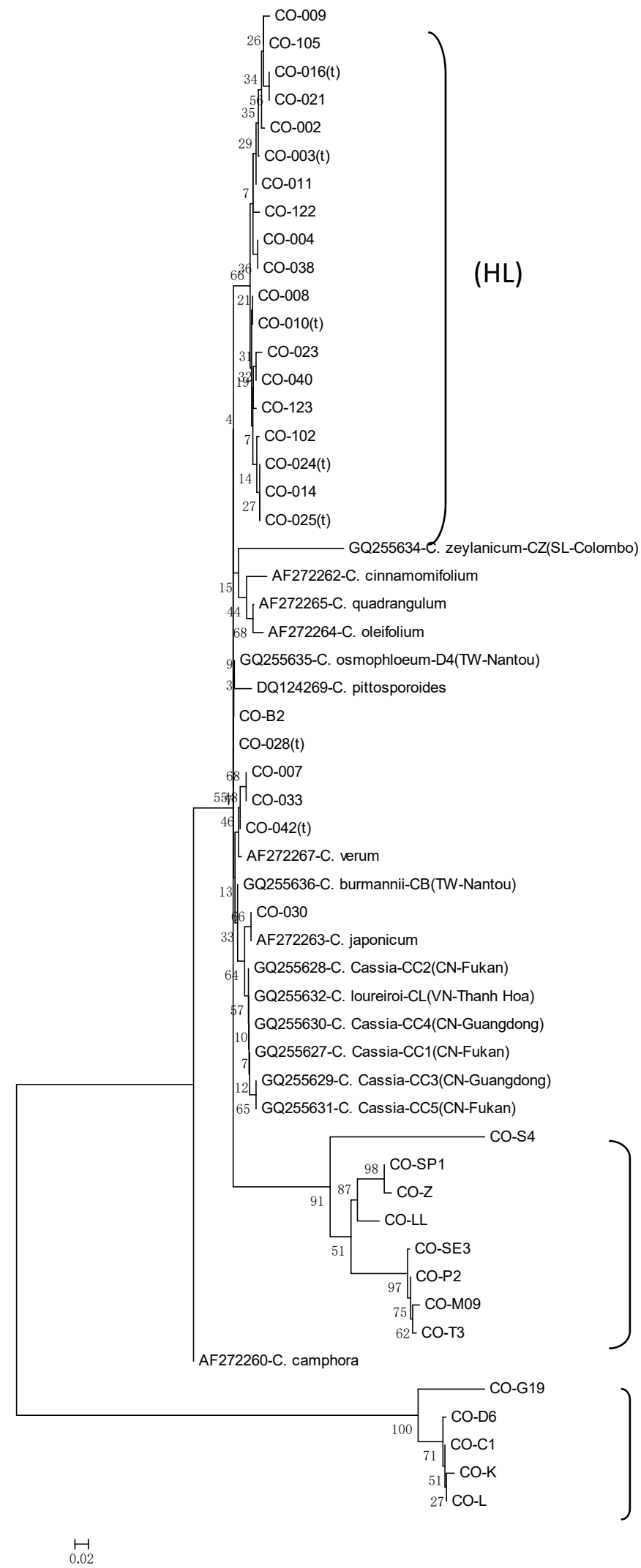

(LHC-1)

(LHC-2)

(A)

Figure 5. Cont. 


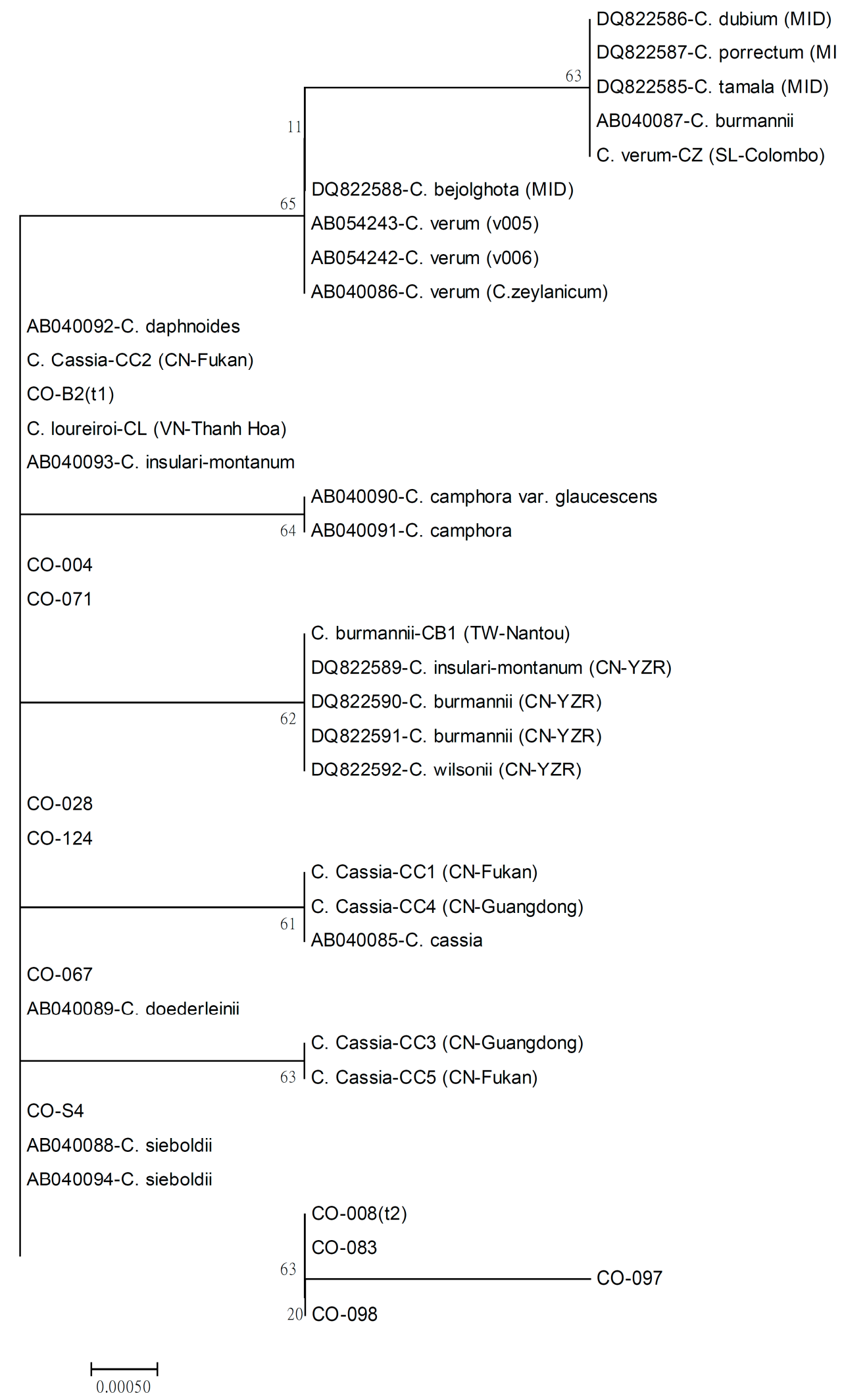

(B)

Figure 5. Cont. 


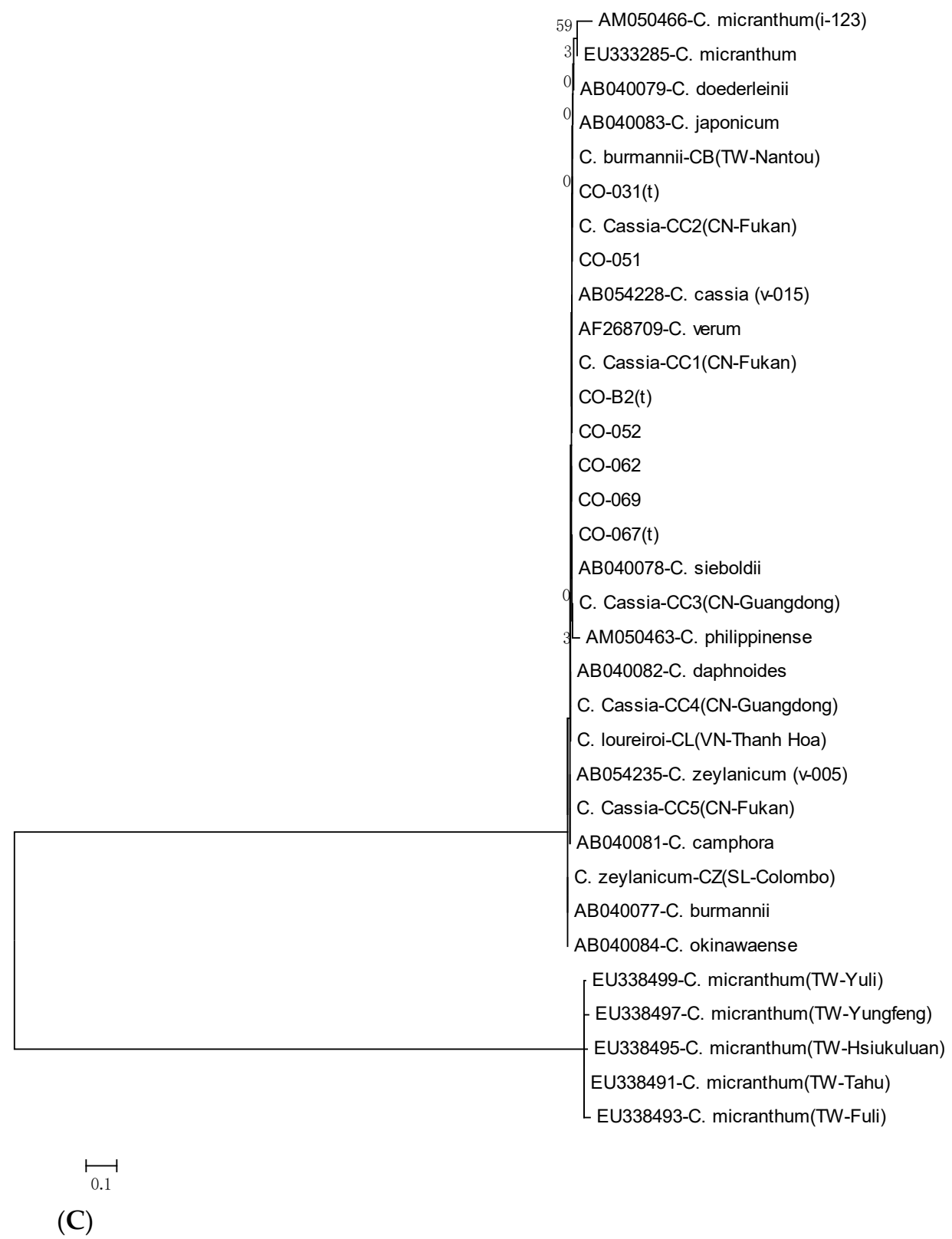

Figure 5. A neighbor-joining tree constructed from the sequences of three molecular markers among Cinnamomum spp. (A) The partial ITS2 sequences, (B) the trnL intron sequences, and (C) the trnL-trnF IGS sequences. The bootstrap values at the nodes of the trees were obtained from 1000 replicates and are shown as percentages. The scale means an estimation of evolutionary distance between them for the best candidate phylogenetic tree.

\subsection{Phylogenetic Analysis and Gene Resource Identification}

The pITS2 sequences of ten Cinnamomum spp. collected from 16 different locations, which were available in GenBank, and the data from the 38 geographical strains of $\mathrm{CO}$ were used to further construct the phylogenetic tree using MP methods for gene resource identification purposes (see Table 1). Based on our results, all of the specimens were properly clustered into seven separate groups at the species level, without an out-group species (Figure 6). Nineteen strains of $\mathrm{CO}$, accounting for $79.2 \%$ of the representative sequences from the HL specimens, were clustered into Group 1 and were phylogenetically related to the one registered sequence from CO (GQ255635). Thirteen strains, accounting for $92.9 \%$ of the representative sequences from the LHC specimens, were clustered into 
Group 6 and were phylogenetically distinct from the strains collected from the HL in Group 1. CO-B2 was the only strain collected from the LHC that was related to the strains collected from the HL in Group 1. CO-030, C. insulari-montanum (AF272263), C. loureiroi-CL (VN-Thanh Hoa) (GQ255632) and five specimens of $C$. Cassia (CC1-CC5) were closely related and clustered into Group 4. The phylogenetic trees constructed from the pITS2 data using the MP method were more accurate than those constructed using the NJ method for the inter- or intraspecific gene resource identification.

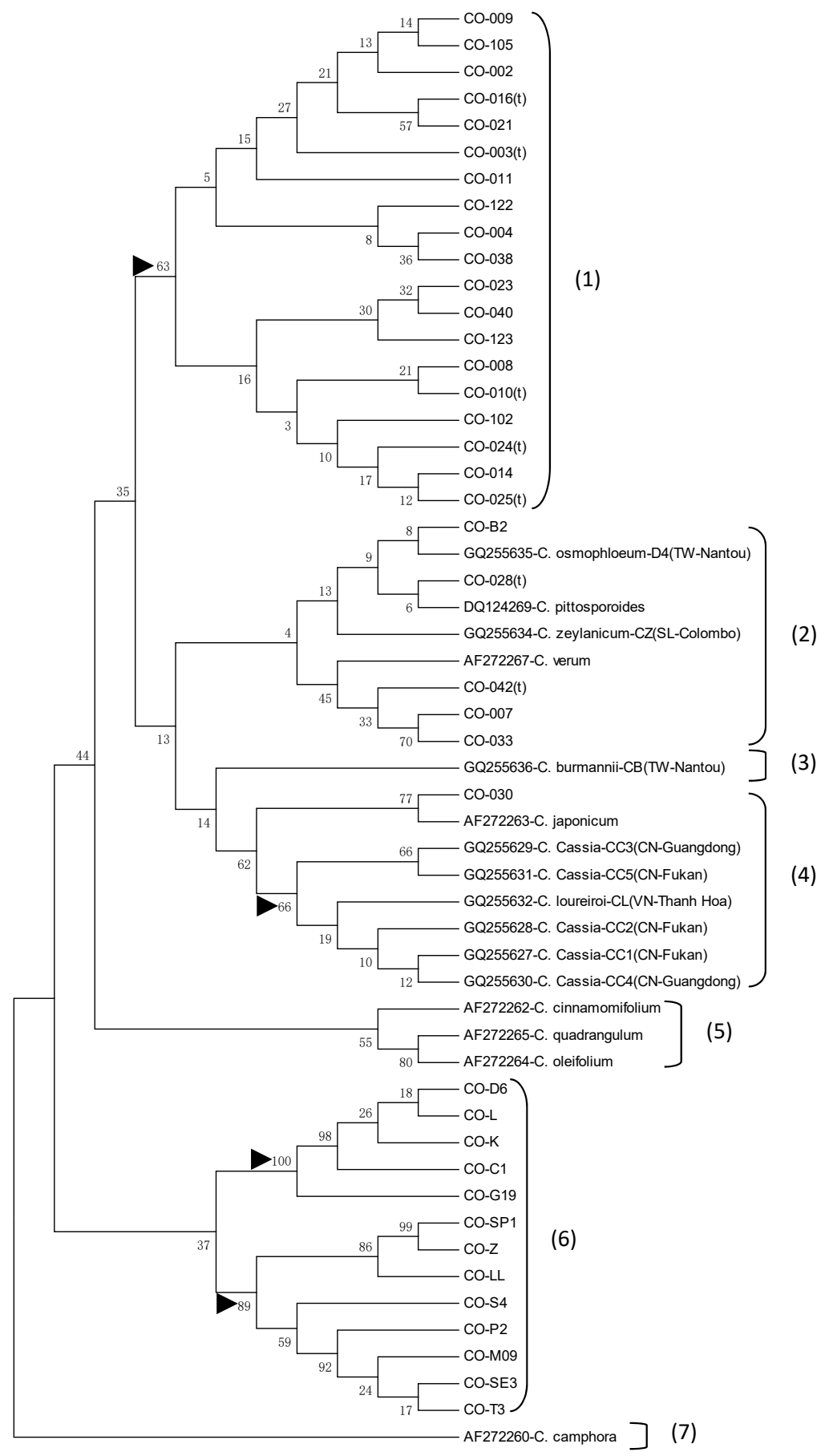

Figure 6. A maximum parsimony tree of the partial ITS2 sequences from the Cinnamomum species used in this study. The bootstrap values at the nodes of the trees were obtained from 1000 replicates and are shown as percentages. 


\section{Discussion}

Cinnamon species in Taiwan have been used heavily for hundreds years. However, in the markets, there is a serious problem regarding fake or misidentified cinnamon materials. These are very difficult to identify from their morphology. There are four indigenous cinnamon species in Taiwan: Cinnamomum osmophloeum, Cinnamomum insulari-montanum Hayata, Cinnamomum pedunculatum Nees, and Cinnamomum macrostemon Hayata [2]. Because of the economic importance of these plants, Dr. Ta-Wei Hu and his colleagues collected geographical strains of $\mathrm{CO}$ from various natural habitats, which were planted in the LHC in 1992. The essential oil extracted from CO trees has received more attention lately because recent studies have revealed that this plant has antifungal, insecticidal, antibacterial, and mosquito larvicidal properties [4-10]. In addition, recent studies have detailed the potential pharmacological uses of compounds from these plants; they are believed to have antitumor, chemoprotective, anti-inflammatory, and antioxidative properties, as well as the ability to relieve blood uric acid levels [11-16]. For these reasons, $\mathrm{CO}$ is a valuable indigenous plant to Taiwan.

Based on phylogenetic analyses and the GC-MS analysis of essential oils extracted from the leaves, researchers have previously reported at least six chemotypes for the geographical strains of $\mathrm{CO}$ in the LHC $[20,21,33]$. Unfortunately, we were previously unsuccessful in authenticating the chemotype classification for specimens of geographical strains of $\mathrm{CO}$ [33]. In the present study, we found that the nucleotide sequence polymorphisms in the ITS2 regions were sufficient to distinguish the geographical strains of CO collected from the LHC (Figure 2). Of the 73 geographical strains tested, there were 31, 8, and 4 unique sequences for the pITS2, trnL intron, and trnL-trnF IGS regions, respectively. CO-004 had two unique sequences in two different marker regions. Therefore, the 43 (total) unique sequences for these three regions were used for the intraspecific molecular identification of 42 out of 73 geographical strains of CO (Figures 2-4). However, more studies will be needed to establish a method for the DNA authentication of chemotypes for the strains of $\mathrm{CO}$.

The sequence identity (ID) in the ITS2 regions was between 0.310 and 0.994 among the geographical strains of CO. Surprisingly, this intraspecific variation was much greater, which ranged from 0.72 to 1.00 . The majority of the variation arose from the strains of $\mathrm{CO}$ collected from the LHC. In contrast, the ID among the strains of CO collected from the HL only ranged between 0.872 and 0.994 , which was reasonably small when compared to that observed among Cinnamomum spp. (Table 3). All of the nucleotide sequences in the trnL intron and trnL-trnF IGS regions were $100 \%$ homologous for the tested specimens of CO from the LHC. Additionally, all of the strains preserved in the LHC have been authenticated and properly labeled. Therefore, our results indicated the presence of great genetic diversity among the geographical strains of $\mathrm{CO}$ that are preserved in the LHC.

For the three DNA regions used in the present study, the nucleotide sequence variations in the trnL-trnG IGS regions were the greatest among the Cinnamomum spp. (Table 3). All of the C. cassia specimens collected from the five locations (CC1-CC5, see Table 1) were determined to have identical trnL-trnG IGS nucleotide sequences. However, the two species C. loureiroi and C. cassia could not be

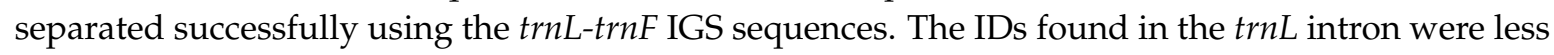
variable (between 0.993 and 1) among the Cinnamomum spp. Many different species have identical trnL intron sequences, such as C. cassia, C. insulari-montanum, C. burmannii and C. wilsonii Sarg. Based on our results, the trnL intron is not a good marker for identifying species, and instead, we recommend ITS2 because it provides better resolution for species identification among Cinnamomum spp.

The leaves of all Cinnamomum species have three-branched veins and are similar in appearance. It would be difficult to distinguish C. osmophloeum, C. insulari-montanum, C. macrostemon, C. subavenium Miq., C. burmannii, and other subspecies from each other in the field, solely based on their leaf morphology; other characteristics, such as the bud scales and the shapes of the perianth and fruits, must be used to facilitate identification. The use of molecular markers can overcome the inherent difficulties of species identification and eliminate misclassification. These molecular markers can be employed for a broad range of purposes, including species identification, phylogenetic studies, the study of systems evolution, and geological phylogenetics [38]. Among ribosomal RNA (rRNA) genes, 
ITS sequences evolve relatively quickly, and the subsequent variation aids in solving interspecies classification issues within genera. In this study, phylogenetic trees were constructed using the NJ method based on three regions of markers to compare Cinnamomum spp. (Figure 5). The genetic distance separating the species was the shortest for the phylogenetic tree constructed based on the $t r n L$ intron because of the lack of nucleotide variation in this region (Figure 5B). The sixteen registered ITS2 sequences for Cinnamomum spp. in the GenBank database were properly clustered and successfully separated at the species level (Figure 5A). However, the geographical strains collected from the LHC were clustered into two different groups (LHC-1 and LHC-2) and were distinct from the strains collected from the HL. The greater genetic diversity of the strains from the LHC could have resulted from its endeavor to create a comprehensive collection reflecting the diversity of $\mathrm{CO}$ in various regions of Taiwan. In contrast, the species from the HL were selected for their superiority.

The phylogenetic tree based on the ITS2 sequence data and constructed using the NJ and parsimony method provided better clustering efficacy for all of the specimens of Cinnamomum spp. (Figure 6). Nineteen of the 24 (79.2\%) representative sequences for strains collected from the HL were clustered together with a bootstrap value of 63 and positioned next to a previously registered sequence of CO-D4 in Group 1. CO-D6 and four other strains were clustered together with a bootstrap value of 100, and CO-SP1 and seven other strains were clustered together with a bootstrap value of 89 . These 13 strains, which accounted for $92.9 \%$ of the representative sequences for strains collected from the LHC, were clustered together in Group 7. In Group 4, we found that C. cassia specimens collected from five different locations in mainland China were clustered together with a bootstrap value of 66 , and these specimens were related to C. loureiroi Nees from Vietnam. We also determined that CO-030 is a close relative of $C$. insulari-montanum. These results indicated that the construction of a phylogenetic tree may be based on the ITS2 sequence variability among Cinnamomum spp. and can be used for molecular identification purposes and the selection of valuable strains among the various geographical strains of CO. ITS2 was proposed as a novel DNA barcode for identifying medicinal plant species [39,40]. DNA barcoding is a rapidly growing area of research. Our results show the value of these markers for barcoding and gene resource identification among Cinnamomum spp, especially for Cinnamomum osmophloeum.

\section{Conclusions}

In conclusion, our study discovers the best region for this species used as DNA barcoding. The Lien Hua-Chin Research Center of the Forest Research Institute and the Hua-Lin Forestry Center of Chinese Culture University are important locations for the preservation of the diversity of geographical strains of Cinnamomum osmophloeum. The ITS2 rDNA local sequence database established in the present study could be used in gene resource identification and the selection of desirable Cinnamomum osmophloeum strains. Our study results can be used further for correctly and rapidly identifying the true Cinnamomum osmophloeum in the front line, and avoid fake Cinnamomum osmophloeum in the markets.

Author Contributions: Conceptualization, Investigation, Writing-Review \& Editing, Supervision, Project Administration, S.-C.L. and P.-L.L.; Methodology, Software, Validation, Formal Analysis, W.-K.H. and P.-L.L.; Resources, Funding Acquisition, S.-C.L.; Data Curation, Visualization, Writing-Original Draft Preparation, W.-K.H., S.-C.L. and P.-L.L.

Acknowledgments: This research was funded by the Ministry of Science and Technology of Taiwan, grant number NSC 96-2317-B-034-001 and by the Council of Agriculture of Taiwan, grant number 99AS-8.4.2-FB-e1-3. We also thank you MIN-YI LIN, CHANG-HUI LEE, JENG-CHUAN YANG, KUEN-YIH HO, YU-HSUAN LEE, and CHIA-WEI LEE for their contribution in this paper. We also appreciate the valuable comments and the constructive suggestions from editors and anonymous reviewers.

Conflicts of Interest: The authors declare no conflict of interest. The funders had no role in the design of the study; in the collection, analyses, or interpretation of data; in the writing of the manuscript, or in the decision to publish the results. 


\section{References}

1. Purseglove, J.W. Lauraceae. In Tropical Crops: Dicotyledons 2, 2nd ed.; Purseglove, J.W., Ed.; Longmans Green and Co. 1td.: London, UK, 1969; pp. 187-192.

2. Liu, Y.J.; Lu, F.Y.; Ou, C.H. Trees of Taiwan; Monographic Publication No. 7; College of Agriculture, National Chung-Hshing University: Taichung, Taiwan, 1988. (In Chinese)

3. Boufford, D.E.; Hsieh, C.F.; Huang, T.C.; Kuoh, C.S.; Ohashi, H.; Peng, C.I.; Tsai, J.L.; Yang, K.C. Flora of Taiwan; National Science Council: Taipei, Taiwan, 2003; Volumn 2, pp. 445-446, (Article in Chinese).

4. Cheng, S.S.; Liu, J.Y.; Tsai, K.H.; Chen, W.J.; Chang, S.T. Chemical composition and mosquito larvicidal activity of essential oils from leaves of different Cinnamomum osmophloeum clones. J. Agric. Food Chem. 2004, 52, 4395-4400. [CrossRef] [PubMed]

5. $\quad$ Cheng, S.S.; Liu, J.Y.; Lin, C.Y.; Hsui, Y.R.; Lu, M.C.; Wu, W.J.; Chang, S.T. Terminating red imported fire ants using Cinnamomum osmophloeum leaf essential oil. Bioresour. Technol. 2008, 99, 889-893. [CrossRef] [PubMed]

6. Cheng, S.S.; Liu, J.Y.; Huang, C.G.; Hsui, Y.R.; Chen, W.J.; Chang, S.T. Insecticidal activities of leaf essential oils from Cinnamomum osmophloeum against three mosquito species. Bioresour. Technol. 2009, 100, 457-464. [CrossRef] [PubMed]

7. Chang, S.T.; Chen, P.F.; Chang, S.C. Antibacterial activity of leaf essential oils and their constituents from Cinnamomum osmophloeum. J. Ethnopharmacol. 2001, 77, 123-127. [CrossRef]

8. Chang, C.W.; Chang, W.L.; Chang, S.T.; Cheng, S.S. Antibacterial activities of plant essential oils against Legionella pneumophila. Water Res. 2008, 42, 278-286. [CrossRef]

9. Wang, S.Y.; Chen, P.F.; Chang, S.T. Antifungal activities of essential oils and their constituents from indigenous cinnamon (Cinnamomum osmophloeum) leaves against wood decay fungi. Bioresour. Technol. 2005, 96, 813-818. [CrossRef]

10. Cheng, S.S.; Liu, J.Y.; Hsui, Y.R.; Chang, S.T. Chemical polymorphism and antifungal activity of essential oils from leaves of different clones of indigenous cinnamon (Cinnamomum osmophloeum). Bioresour. Technol. 2006, 97, 306-312. [CrossRef]

11. Shen, Y.C.; Chou, C.J.; Wang, Y.H.; Chen, C.F.; Chou, Y.C.; Lu, M.K. Anti-inflammatory activity of the extracts from mycelia of Antrodia camphorata cultured with water-soluble fractions from five different Cinnamomum species. FEMS Microbiol. Lett. 2004, 231, 137-143. [CrossRef]

12. Chao, L.K.; Hua, K.F.; Hsu, H.Y.; Cheng, S.S.; Liu, J.Y.; Chang, S.T. Study on the anti-inflammatory activity of essential oil from leaves of Cinnamomum osmophloeum. J. Agric. Food Chem. 2005, 53, 7274-7278. [CrossRef] [PubMed]

13. Fang, S.H.; Rao, Y.K.; Tzeng, Y.M. Inhibitory effects of flavonol glycosides from Cinnamomum osmophloeum on inflammatory mediators in LPS/IFN-gamma-activated murine macrophages. Bioorg. Med. Chem. 2005, 13, 2381-2388. [CrossRef]

14. Rao, Y.K.; Fang, S.H.; Tzeng, Y.M. Evaluation of the anti-inflammatory and anti-proliferation tumoral cells activities of Antrodia camphorata, Cordyceps sinensis, and Cinnamomum osmophloeum bark extracts. J. Ethnopharmacol. 2007, 114, 78-85. [CrossRef]

15. Chao, L.K.; Hua, K.F.; Hsu, H.Y.; Cheng, S.S.; Lin, I.F.; Chen, C.J.; Chen, S.T.; Chang, S.T. Cinnamaldehyde inhibits pro-inf lammatory cytokines secretion from monocytes/macrophages through suppression of intracellular signaling. Food Chem. Toxicol. 2008, 46, 220-231. [CrossRef]

16. Tung, Y.T.; Yen, P.L.; Lin, C.Y.; Chang, S.T. Anti-inflammatory activities of essential oils and their constituents from different provenances of indigenous cinnamon (Cinnamomum osmophloeum) leaves. Pharm. Biol. 2010, 48, 1130-1136. [CrossRef] [PubMed]

17. Wang, S.Y.; Yang, C.W.; Liao, J.W.; Zhen, W.W.; Chu, F.H.; Chang, S.T. Essential oil from leaves of Cinnamomum osmophloeum acts as a xanthine oxidase inhibitor and reduces the serum uric acid levels in oxonate-induced mice. Phytomedicine 2008, 15, 940-945. [CrossRef]

18. Chao, L.K.; Chang, W.T.; Shih, Y.W.; Huang, J.S. Cinnamaldehyde impairs high glucose-induced hypertrophy in renal interstitial fibroblasts. Toxicol. Appl. Pharmacol. 2010, 244, 174-180. [CrossRef] [PubMed]

19. Hu, T.W. Distribution, Collection and the Germplasm Preservation of Cinnamomum osmophloeum Kaneh. In Monograph of Cinnamomum osmophloeum Kaneh.; Lin, T.P., Ed.; Taiwan Forestry Research Institute: Taipei, Taiwan, 1992; pp. 1-6. (In Chinese) 
20. Lee, H.C.; Chen, S.S.; Liu, J.Y.; Chang, S.T. Chemical polymorphism of leaf essential oils from different geographical clones of indigenous cinnamon (Cinnamomum osmophloeum). Q. J. Chin. Fore. 2003, 36, 411-422.

21. Cheng, S.S.; Lin, C.Y.; Wang, Y.N.; Hsui, Y.R.; Chang, S.T. Set-up of the Source Bank of Cinnamomum osmophloeum-Chemical Polymorphism and Composition of Leaf Essential Oils. J. Exp. For. Nat. Taiwan Univ. 2008, 22, 21-34.

22. White, T.J.; Bruns, T.; Lee, S.; Taylor, J. Amplification and Direct Sequencing of Fungal Ribosomal RNA Genes for Phylogenetics. In PCR Protocols: A Guide to Methods and Applications; Innis, M.A., Gelfand, D.H., Sninsky, J.J., White, T.J., Eds.; Academic Press: New York, NY, USA, 1990; pp. 315-322.

23. Alvarez, I.; Wendel, J.F. Ribosomal ITS sequences and plant phylogenetic inference. Mol. Phylogenet. Evol. 2003, 29, 417-434. [CrossRef]

24. Lau, D.T.; Shaw, P.C.; Wang, J.; But, P.P. Authentication of medicinal Dendrobium species by the internal transcribed spacer of ribosomal DNA. Planta Med. 2001, 67, 456-460.

25. Chiou, S.J.; Yen, J.H.; Fang, C.L.; Chen, H.L.; Lin, T.Y. Authentication of medicinal herbs using PCR-amplified ITS2 with specific primers. Planta Med. 2007, 73, 1421-1426. [CrossRef]

26. Saini, A.; Reddy, S.K.; Jawali, N. Intra-individual and intra-species heterogeneity in nuclear rDNA ITS region of Vigna species from subgenus Ceratotropis. Genet. Res. (Camb) 2008, 90, 299-316. [CrossRef]

27. Taberlet, P.; Gielly, L.; Pautou, G.; Bouvet, J. Universal primers for amplification of three noncoding regions of chloroplast DNA. Plant Mol. Biol. 1991, 17, 1105-1109. [CrossRef] [PubMed]

28. Zhen, Y.; Andolfatto, P. Methods to detect selection on noncoding DNA. Methods Mol. Biol. 2012, 856, 141-159.

29. Fukuda, T.; Yokoyama, J.; Ohashi, H. Phylogeny and biogeography of the genus Lycium (Solanaceae): Inferences from chloroplast DNA sequences. Mol. Phylogenet. Evol. 2001, 19, 246-258. [CrossRef]

30. Yi, T.; Miller, A.J.; Wen, J. Phylogenetic and biogeographic diversification of Rhus (Anacardiaceae) in the Northern Hemisphere. Mol. Phylogenet. Evol. 2004, 33, 861-879. [CrossRef]

31. Kojoma, M.; Kurihara, K.; Yamada, K.; Sekita, S.; Satake, M.; Iida, O. Genetic identification of cinnamon (Cinnamomum spp.) based on the trnLtrnF chloroplast DNA. Planta Med. 2002, 68, 94-96. [CrossRef]

32. Tsai, L.C.; Yu, Y.C.; Hsieh, H.M.; Wang, J.C.; Linacre, A.; Lee, J.C. Species identification using sequences of the trnL intron and the trnL-trnF IGS of chloroplast genome among popular plants in Taiwan. Forensic Sci. Int. 2006, 164, 193-200. [CrossRef]

33. Lee, S.C.; Chiou, S.J.; Yen, J.H.; Lin, T.Y.; Hsieh, K.T.; Yang, J.C. DNA barcoding Cinnamomum osmophloeum Kaneh. based on the partial noncoding ITS2 region of ribosomal genes. J. Food Drug Anal. 2010, 18, 128-135.

34. Lee, S.C.; Lee, C.H.; Lin, M.Y.; Ho, K.Y. Genetic identification of Cinnamomum species based on partial internal transcribed spacer 2 of ribosomal DNA. J. Food Drug Anal. 2010, 18, 225-231.

35. Cubero, O.F.; Crespo, A.; Fatehi, J.; Bridge, P.D. DNA extraction and PCR amplification method suitable for fresh, herbarium-stored, lichenized, and other fungi. Plant Syst. Evol. 1999, 216, 243-249. [CrossRef]

36. Hall, T.A. BioEdit: A user-friendly biological sequence alignment editor and analysis program for Windows 95/98/NT. Nucl. Acids. Symp. Ser. 1999, 41, 95-98.

37. Kumar, S.; Stecher, G.; Tamura, K. MEGA7: Molecular Evolutionary Genetics Analysis Version 7.0 for Bigger Datasets. Mol. Biol. Evol. 2016, 33, 1870-1874. [CrossRef] [PubMed]

38. Yip, P.Y.; Chau, C.F.; Mak, C.Y.; Kwan, H.S. DNA methods for identification of Chinese medicinal materials. Chin. Med. 2007, 2, 9. [CrossRef]

39. Yao, H.; Song, J.; Liu, C.; Luo, K.; Han, J.; Li, Y.; Pang, X.; Xu, H.; Zhu, Y.; Xiao, P.; et al. Use of ITS2 region as the universal DNA barcode for plants and animals. PLoS ONE 2010, 5, e13102. [CrossRef] [PubMed]

40. Chen, S.; Yao, H.; Han, J.; Liu, C.; Song, J.; Shi, L.; Zhu, Y.; Ma, X.; Gao, T.; Pang, X.; et al. Validation of the ITS2 region as a novel DNA barcode for identifying medicinal plant species. PLoS ONE 2010, 5, e8613. [CrossRef] [PubMed]

(C) 2019 by the authors. Licensee MDPI, Basel, Switzerland. This article is an open access article distributed under the terms and conditions of the Creative Commons Attribution (CC BY) license (http:/ / creativecommons.org/licenses/by/4.0/). 